Working Paper/Document de travail 2013-19

\title{
Business Cycle Effects of Credit Shocks in a DSGE Model with Firm Defaults
}

by M. Hashem Pesaran and TengTeng Xu 
Bank of Canada Working Paper 2013-19

June 2013

\title{
Business Cycle Effects of Credit Shocks in a DSGE Model with Firm Defaults
}

\author{
by \\ M. Hashem Pesaran ${ }^{1}$ and TengTeng $X u^{2}$ \\ 1 University of Southern California and University of Cambridge \\ Dana and David Dornsife College of Letters, Arts and Sciences \\ Los Angeles, CA 90089-4012 \\ pesaran@usc.edu \\ 2International Economic Analysis Department \\ Bank of Canada \\ Ottawa, Ontario, Canada K1A 0G9 \\ and \\ CIMF \\ txu@bankofcanada.ca
}

Bank of Canada working papers are theoretical or empirical works-in-progress on subjects in economics and finance. The views expressed in this paper are those of the authors. No responsibility for them should be attributed to the Bank of Canada. 


\section{Acknowledgements}

The authors would like to thank Paul Beaudry, Oliver de Groot, Michael B. Devereux, Dapeng Gu, Sean Holly, Serguei Maliar, Matthias Paustian, Alessandro Rebucci, Sergejs Saksonovs, Gregor Smith, Malik Shukayev, Ron Smith, Anna Watson and seminar participants at the Royal Economic Society Annual Meetings 2012, the Midwest Macroeconomics Meetings 2012, the American Economic Association Annual Meetings 2013, the Inter-American Development Bank, and the Bank of England for useful discussions and helpful comments. 


\begin{abstract}
This paper proposes a theoretical framework to analyze the relationship between credit shocks, firm defaults and volatility, and to study the impact of credit shocks on business cycle dynamics. Firms are identical ex ante but differ ex post due to different realizations of firm-specific technology shocks, possibly leading to default by some firms. The paper advances a new modelling approach for the analysis of firm defaults and financial intermediation that takes account of the financial implications of such defaults for both households and banks. Results from a calibrated version of the model suggest that, in the steady state, a firm's default probability rises with its leverage ratio and the level of uncertainty in the economy. A positive credit shock, defined as a rise in the loan-todeposit ratio, increases output, consumption, hours and productivity, and reduces the spread between loan and deposit rates. The effects of the credit shock tend to be highly persistent, even without price rigidities and habit persistence in consumption behavior.

JEL classification: E32, E44, G21

Bank classification: Business fluctuations and cycles; Economic models; Credit and credit aggregates; Financial institutions
\end{abstract}

\title{
Résumé
}

Les auteurs proposent un modèle théorique pour l'analyse de la relation entre les chocs de crédit, les défaillances d'entreprises et la volatilité, ainsi que pour l'étude des effets de ces chocs sur la dynamique du cycle économique. Dans ce modèle, des entreprises identiques ex ante se différencient ex post en réponse aux chocs technologiques réalisés, qui sont propres à chaque entreprise et peuvent provoquer sa défaillance. Le nouveau modèle employé par les auteurs pour examiner les défaillances des firmes et l'intermédiation financière tient compte des conséquences financières de ces défaillances à la fois sur les ménages et sur les banques. Les résultats tirés d'une version étalonnée du modèle indiquent qu'à l'équilibre de long terme, la probabilité de défaut d'une entreprise augmente avec son ratio de levier et le degré d'incertitude dans l'économie. Un choc de crédit positif - à savoir une hausse du ratio des prêts aux dépôts - accroît la production, la consommation, le nombre d'heures travaillées et la productivité et réduit l'écart entre le taux prêteur et le taux de rémunération des dépôts. Les retombées du choc de crédit tendent à perdurer longtemps même en l'absence de rigidité des prix et de persistance des habitudes de consommation.

Classification JEL : E32, E44, G21

Classification de la Banque : Cycles et fluctuations économiques; Modèles économiques; Crédit et agrégats du crédit; Institutions financières 


\section{Introduction}

The recent financial crisis and the ensuing economic recession have highlighted the importance of interlinkages between financial markets and the real economy, in particular, the role of private credit in the transmission of real and financial shocks. Empirical evidence suggests that bank credit has played an important role in explaining the business-cycle dynamics of output growth, inflation and interest rates in advanced economies since the late 1970s. As shown in Helbling, Huidrom, Kose, and Otrok (2011), Bagliano and Morana (2012) and Xu (2012), a negative shock to U.S. real credit has significant adverse effects on output and interest rates in the United States, as well as in other advanced economies such as the euro area and the United Kingdom. The contraction in credit and the subsequent decline in output during the 2007-2009 crisis was coupled with a rise in the frequency of a firm's default. In fact, according to Moody's (2012), the rolling 12-month default rate for private firms in the United States reached a peak of 5.3 per cent in September 2009, more than double the pre-crisis level. In addition, market volatility, as measured by the VIX index, reached elevated levels during the crisis, peaking at 80 toward the end of 2008, compared with an average of 20 in the five years preceding the crisis. The Federal Open Market Committee repeatedly emphasized the increased uncertainty as one of the key factors driving the 2007-2009 recession.

Over the past two decades, there have been important advances in the theoretical literature on the macroeconomic impact of financial frictions. Notable contributions to the literature include Kiyotaki and Moore (1997), Bernanke, Gertler, and Gilchrist (1999), Christiano, Ilut, Motto, and Rostagno (2010), Carlstrom, Fuerst, and Paustian (2010), Curdia and Woodford (2010) and Gertler and Kiyotaki (2010). This research shows that credit market frictions (due to information asymmetry, agency costs or collateral constraints) act as a financial accelerator that in turn leads to an amplification of business cycles, and highlights the mechanisms through which credit market conditions are likely to impact the real economy. In addition, recent literature that models the banking sector sheds light on the relationship between bank lending and investment decisions by firms, and how credit risks relate to the pricing of bank loans. See, for example, Freixas and Rochet (2008) and Pesaran, Schuermann, Treutler, and Weiner (2006).

The existing literature on financial frictions is largely monetary in nature and is aimed mainly at obtaining a better understanding of the transmission mechanisms for monetary policy shocks. They are motivated by the limitations of traditional demand side monetary models in matching VAR-based empirical evidence of the effects of monetary policy shocks. See, for example Bernanke and Gertler (1995), and Bernanke, Gertler, and Gilchrist (1999). Recently, a number of papers have developed models with financial frictions to investigate the effects of unconventional monetary policy, such as the direct lending by central banks that took place during the 2008 financial crisis. Notable examples are Christiano, Ilut, Motto, and Rostagno (2010), Gertler and Kiyotaki (2010) and Gertler and Karadi (2011, 2013).

In this paper, we have a different focus and examine the relationships among credit, firm default and volatility (the three important factors in the recent financial crisis), and study the impact of a credit shock on the macroeconomy. To this end, we develop a theoretical model with financial intermediation, allowing for the possibility of firm defaults, and accounting for secondorder moments (volatility) of shocks to the macroeconomic environment. 
The main contribution of the paper in relation to the existing literature is twofold. First, we advance an alternative modelling framework for the analysis of firm defaults and financial intermediation that establishes a direct link between credit risk and productivity. The proposed framework comprises a large number of firms, a representative household and a banking sector that operates competitively. Firms are identical ex ante and live from period to period. At the start of each period, firms enter the market and decide on the optimal levels of labour input and capital stock for their operations. Firms receive initial funds from the household sector, which can be interpreted as private-equity investment from the household, and augment these funds by borrowing from the banking sector. These financing arrangements are made prior to the realization of idiosyncratic and common technology shocks. Some firms may default if the realized technology shocks are unfavorable, such that the firm's revenue is not sufficient to repay the bank loan. We assume that the product market is competitive and, while some firms may fail at the end of each period, entry is free. The banking sector receives deposits from households before the arrival of a credit shock, which then determines the total level of loanable funds to the firms. The banking sector receives loan repayments from solvent firms and seizes the revenues of defaulted firms (if any) to partially cover losses. The equilibrium loan rate is in turn affected by the economy-wide default probability.

Our modelling approach is different from models in the literature that consider collateral constraints. See, for example, Kiyotaki and Moore (1997), Gertler and Kiyotaki (2010), and Carlstrom, Fuerst, and Paustian (2010). In these studies, collateral constraints are introduced as a way of ensuring that borrowers can re-pay their debts, which in most cases rule out, almost by design, the possibility of firm default in equilibrium. Our paper is more closely related to the work by Freixas and Rochet (2008) on the microeconomics of banking, and Bernanke, Gertler, and Gilchrist (1999, BGG) , on modelling the producer sector and firm defaults. ${ }^{1}$ In modelling firm defaults, our approach differs from Bernanke, Gertler, and Gilchrist (1999), BGG, in that idiosyncratic shocks affect productivity rather than the return on capital, which keeps the model tractable and establishes a direct link between credit risk and productivity. We allow households to bear part of the default risk in the face of an adverse technology shock, through their equity investment in firms; otherwise, the whole burden of default falls on the banking sector, resulting in excessively large spreads between loan rates and deposit rates. The timing of labour and capital decisions and the fact that firms are subject to idiosyncratic technology shocks are essential for modelling firm defaults in equilibrium. ${ }^{2}$

Second, the paper contributes to the analysis of steady states in model economies that takes account of non-linearities and possible unit roots in the economy-wide technology processes. One feature of the standard first-order perturbation approach is that the solution displays the certainty equivalence property, where the first-order approximation to the unconditional means of endogenous variables coincides with their non-stochastic steady-state values and rules out a risk premium in stochastic environments (Schmitt-Grohe and Uribe, 2004). We propose an alternative method

\footnotetext{
${ }^{1}$ Other related papers that allow for the possibility of firm defaults include Fiore and Tristani (2009) and Christiano, Ilut, Motto, and Rostagno (2010).

${ }^{2}$ Equilibrium default models have existed in the sovereign debt literature, including Arellano (2008), Sandleris (2008) and Yue (2010), while Chatterjee, Corbae, Nakajima, and Ros-Rull (2007) studied default in the context of unsecured household debt. The focus of our paper differs, since we are interested in examining the impact of equilibrium default in the firm sector, rather than the sovereign or household sectors.
} 
where the steady-state relations of the model are derived from unconditional expectations of the model's relations in terms of the log of the variables measured in efficiency units. Using this approach and the properties of the log normal distribution, we are able to express the steady state of shocks as a function of their mean and standard deviation, therefore allowing for explicit consideration of risks in the steady state, without using second- or higher-order perturbation methods (see, for example, Schmitt-Grohe and Uribe, 2004 and Devereux and Sutherland, 2011). This approach to modelling steady states enables us to study the link between credit shock and volatility and sheds light on the impact of credit shocks on the macroeconomy during periods of high market uncertainty.

The main findings of our paper are as follows. First, in the steady state, the firm default probability rises with firms' leverage ratio and the level of uncertainty in the economy (measured by the standard deviation of idiosyncratic and common technology shocks). As firms become more leveraged, consumption, output and capital decline, despite a rise in the level of loans, since a larger proportion of the loans are non-performing. The level of output, loans and consumption also decline with increased uncertainty.

Second, we are able to generate theoretical impulse responses to a credit shock that are in line with empirical results on the responses of output and short-term interest rates to a U.S. credit

shock. A positive credit shock can be viewed as a sudden increase in the level of bank loans relative to bank deposits, probably due to an increase in liquidity provision by the banking sector or the central bank. The rise in the level of the loan-to-deposit ratio leads to an increase in the available capital in the economy and, consequently, an expansion in investment and output, which is largely consistent with the empirical results in $\mathrm{Xu}$ (2012). The increase in the level of loanable funds also drives down the loan rate and narrows the spread between the loan rate and deposit rate. Labour hours rise on impact, which leads to higher household incomes and consequently more consumption. Our calibrated results show that the impact of a credit shock on output and consumption can be quite large, with the speed of convergence to equilibrium typically slow (more than 20 quarters). Our finding is consistent with empirical studies of the output effect of financial crises, which suggest that recessions associated with financial crises have been more severe and longer lasting than recessions associated with other shocks (see, for example, IMF, World Economic Outlook, April 2009, Chapter 3). The prolonged impact of the credit shock also reflects the high persistence in the loan-to-deposit ratio that we observe empirically.

The rest of the paper is organized as follows. Section 2 presents the DSGE model of credit, leverage and default. Section 3 sets out the first-order equilibrium conditions, derives the steady states, and describes the solution of the model. Section 4 discusses the parameterizations of the model for the calibration exercises. Section 5 provides the key results on the impulse responses of positive credit shocks. Section 6 provides a brief review of the relevant literature. Section 7 offers some concluding remarks.

\section{A Model of Credit and Default}

We consider an economy comprising a large number of firms, one representative household and a competitive banking sector characterized by one representative bank. Firms are identical ex ante and operate over a single period. At the beginning of each period, firms enter the market and 
decide the optimal levels of labour and capital inputs, before the technology and credit shocks are realized. The capital investment is financed by borrowing from the banking sector, as well as a capital injection from the household at the start of the period. The funds invested by the household can be viewed as "private equity". Technology shocks then arrive and firms combine technology with capital and labour to produce a single output. Firms may default if the technology shock is unfavorable, such that the firm's revenue is insufficient to repay its debt (principal and interest charges) to the banking sector. We assume that the product market is fully competitive and, while some firms may fail each period, entry is free. The representative household consumes, receives interest on its deposits held with the banks, wage payment for its labour services, and an ex post lump-sum transfer (that could be negative) from firms at the end of the period. ${ }^{3}$ The banking sector takes deposits from the household at the beginning of the period, before the realization of a credit shock to the bank's balance sheet that affects the supply of loanable funds available to the firms. The banking sector receives interest and loan repayments from non-defaulted firms at the end of the period and seizes the revenue (if any) of defaulted firms to partially cover its losses.

\subsection{The household sector}

For the household decision, we consider the following standard optimization problem:

$$
\max _{\left\{C_{t+j}, N_{t+j}, j=0,1,2 \ldots\right\}} E\left[\sum_{j=0}^{\infty} \beta^{j} U\left(C_{t+j}, N_{t+j}\right) \mid \Omega_{c t}\right],
$$

subject to the budget constraint

$$
D_{t+1}=\left(1+r_{d t}\right) D_{t}+W_{t} N_{t}-C_{t}-S_{t}+\Pi_{t c}
$$

where $U\left(C_{t}, N_{t}\right)$ is the one-period (instantaneous) utility function, $C_{t}$ is the real consumption expenditure, $N_{t}$ is labour hours and $W_{t}$ is the real wage rate paid for household labour. $D_{t}$ is the household's holding of real deposits with the banking sector at the beginning of time $t, r_{d t}$ is the real return on deposits in period $t$, which is known at time $t . S_{t}$ is household's real equity investment (private equity) in the firms at the beginning of time $t$, and $\Pi_{t c}$ is the household's lumpsum transfer from firms, realized at the end of period t. ${ }^{4}$ Finally, $\beta$ is the discount factor, where $0<\beta<1$, and $E\left(\cdot \mid \Omega_{c t}\right)$ denotes the mathematical conditional expectations operator with respect to the non-decreasing information set $\Omega_{c t}$, to be defined later. Note that we abstract from the endogenous determination of equity holdings for the household sector to keep the model tractable and assume that the household supplies an amount of equity that is determined by an exogenous leverage factor. As we shall see later, it is important to consider equity finance in addition to debt finance in this model; otherwise, we shall end up with excessively wide interest rate spreads and unexpectedly high default probability.

We adopt the following specification of the utility function, popularized by Greenwood, Her-

\footnotetext{
${ }^{3}$ Non-defaulted firms transfer any excess profits to the household sector. The transfer from defaulted firms can be negative, depending on the realization of technology shocks. Resource transfers and default settlements will be discussed in detail later.

${ }^{4}$ The implicit rate of return on the household's private-equity investment is given by $\Pi_{t c} / S_{t}-1$.
} 
cowitz, and Huffman (1988, p.10),

$$
U\left(C_{t}, N_{t}\right)=\frac{1}{1-\gamma}\left[\left(C_{t}-\frac{\chi_{0}}{1+\chi} N_{t}^{1+\chi}\right)^{1-\gamma}-1\right]
$$

where $\gamma>0$ is the coefficient of relative risk aversion and $1 / \chi$ corresponds to the intertemporal elasticity of substitution in labour supply, $\chi>0$. Following Christiano, Eichenbaum, and Evans (1997, p.1221), we have introduced a scaling parameter $\chi_{0}>0$ in $(2.3)$, which is calibrated with other model parameters. ${ }^{5}$ One important property of this form of utility function is that the marginal rate of substitution between consumption and labour effort depends only on labour input. Technically, this makes it easy to solve for $N_{t}$, given the real wage:

$$
-\frac{U_{N}\left(C_{t}, N_{t}\right)}{U_{C}\left(C_{t}, N_{t}\right)}=\chi_{0} N_{t}^{\chi}
$$

so that labour effort is determined independently of the inter-temporal consumption-savings choice. As we shall see later, this function implies a labour-supply schedule that depends on the real wage only and not on consumption.

The information set available to the household sector at the beginning of period $t, \Omega_{c t}$, can be decomposed into a common component $\Psi_{t-1}$, and a private component $\Theta_{c t}$, which is composed of information that is known only to the consumer at time $t$ (but not necessarily to all the other agents), $\Omega_{c t}=\Psi_{t-1} \cup \Theta_{c t}$, where $\Theta_{c t}=\left\{\Pi_{t c}, \Pi_{t-1, c}, \ldots ; S_{t}, S_{t-1}, \ldots ; C_{t} ; D_{t+1}, D_{t} ; W_{t} ; N_{t} ; r_{d t}\right\}$. The common information set $\Psi_{t-1}$ is publicly available and will be specified later.

The solution to the consumer's optimization problem is obtained using the first-order conditions with respect to $C_{t}, D_{t+1}$ and $N_{t}$. Specifically, we end up with (2.2) and the following equations:

$$
\begin{aligned}
E\left[\beta\left(\frac{C_{t+1}-\frac{\chi_{0}}{1+\chi} N_{t+1}^{1+\chi}}{C_{t}-\frac{\chi_{0}}{1+\chi} N_{t}^{1+\chi}}\right)^{-\gamma}\left(1+r_{d, t+1}\right) \mid \Omega_{c t}\right] & =1, \\
W_{t} & =\chi_{0} N_{t}^{\chi} .
\end{aligned}
$$

\section{$2.2 \quad$ Firms}

\subsubsection{Firms' optimization problem}

Each firm $i$ is endowed with the following production technology,

$$
Y_{i t}=Z_{i t}^{\varphi} N_{i t}^{1-\alpha} K_{i t}^{\alpha}, \text { for } i=1,2, \ldots, m
$$

where $K_{i t}$ and $N_{i t}$ are capital and labour inputs, respectively, for firm $i$ in period $t ; Y_{i t}$ is output for firm $i$ in period $t ; \alpha$ is the share of capital; and $\varphi$ is a constant to be determined subsequently.

The technology variable, $Z_{i t}$, is decomposed into an idiosyncratic component, $\Lambda_{i t}$, and a common business-cycle component, $A_{t}$; that is,

$$
Z_{i t}=\Lambda_{i t} A_{t}
$$

\footnotetext{
${ }^{5}$ For other examples of this form of utility function, see Meng and Velasco (2003) and Chapter 3 of Heer and Maussner (2005).
} 
It is further assumed that

$$
A_{t}=A_{t-1} \exp \left(\mu+u_{t}\right)
$$

where $u_{t}$ is a serially correlated common technology shock that follows the first-order autoregressive process,

$$
u_{t}=\rho_{u} u_{t-1}+\varepsilon_{t}, \quad \text { where } \varepsilon_{t} \sim \mathbb{N}\left(0, \sigma_{\varepsilon}^{2}\right), \text { and }\left|\rho_{u}\right|<1 .
$$

The degree of serial correlation in the common technology shock, $u_{t}$, is determined by the autoregressive parameter, $\rho_{u}$.

Let $a_{t}=\ln A_{t}$, then the business-cycle component of the technology shock can be written as

$$
a_{t}=a_{t-1}+\mu+\rho_{u} u_{t-1}+\varepsilon_{t} .
$$

Also let $\lambda_{i t}=\ln \Lambda_{i t}$, and assume that $\lambda_{i t}$ is serially uncorrelated and independently and identically distributed across firms, $\lambda_{i t} \sim \operatorname{iid}\left(0, \sigma_{\lambda}^{2}\right)$. Without loss of generality we also assume that $\varepsilon_{t}$ and $\lambda_{i t}$ are independently distributed. Thus, $z_{i t}=\ln Z_{i t}=\lambda_{i t}+a_{t}$, can be viewed as a single factor model where the common factor, $a_{t}$, is assumed to follow a unit root process. In this sense the specification of technology is quite general and encompasses many other specifications entertained in the theoretical macroeconomic literature.

Firms decide on capital and labour inputs before the arrival of the technology shock, $Z_{i t}$. Further, part of the capital is financed through the equity investment from the household sector at the beginning of each period, denoted by $S_{i t}$, and the rest is borrowed from the banking sector, $L_{i t} \geq 0$; therefore,

$$
K_{i t}=L_{i t}+S_{i t} .
$$

The consumer's contribution to capital acquisition can be viewed as private-equity investment with possible gains/losses to be settled at the end of the period, once the shocks are realized. Note that we assume that firms are owned by the household. From the household's viewpoint, the leverage ratio of firm $i$ is given by $v_{i}=K_{i t} / S_{i t}$, and equation (2.11) implies that $v_{i} \geq 1$ for non-negative $L_{i t}$. The share of capital financed by the banking sector is then given by

$$
L_{i t}=\left(\frac{v_{i}-1}{v_{i}}\right) K_{i t}
$$

We assume that the leverage ratio of the firm is exogenously given and is time-invariant in this version of the paper. It is easy to allow for time variation in $v_{i}$, as long as it is assumed exogenous. An endogenous formulation of the leverage ratio is also of interest but will not be attempted here, since it falls outside the scope of the present paper.

Note that banks cannot observe the idiosyncratic technology shocks $\Lambda_{i t}$, and as a result firms are treated the same ex ante and receive an equal amount, $L_{i t}$, from the banking sector. We also assume that the technology shock, $Z_{i t}$, is not known to firm $i$ when choosing the optimal level of labour and capital. The sequence of events is as follows: firms enter at the beginning of each period $t$, with commitment from the household regarding private-equity finance, borrow from the banking sector and acquire capital; then technology shocks arrive, and firms produce, sell output and pay wages to the households. Firms either default or do not default, depending on the size of the technology shocks, which we will discuss in detail later. 
Having the firms acquire their entire capital stock, $K_{i t}$, at the beginning of each period $t$ (together with the assumption of full depreciation of capital) is a modelling device to ensure that firms are identical ex ante in each period $t$. It is also assumed that firms transfer any excess profits to the household sector, so that a favorable technology shock to firm $i$ at time $t-1$ does not make firm $i$ better off at the beginning of time $t$, relative to the other firms. The one-period nature of the firms' problem enables us to model firm defaults in a tractable manner.

For each firm $i, K_{i t}$ and $N_{i t}$ are derived by solving the following optimization problem:

$$
\max _{\left\{K_{\left.i, t+s, N_{i, t+s,}, s=0,1,2 \ldots\right\}}\right.} E\left(\sum_{s=0}^{\infty} m_{t+s} \Pi_{f, i, t+s} \mid \Omega_{f, i t}\right),
$$

where $\Omega_{f, i t}$ is the information set available to firm $i$ at the beginning of time $t, m_{t+s}$ is the stochastic discount factor (under the assumption that the representative household owns the firms). ${ }^{6}$ The firm's profit function, $\Pi_{f, i t}$, is given by

$$
\Pi_{f, i t}=Y_{i t}-W_{t} N_{i t}-\left(1+r_{k t}\right) K_{i t},
$$

where $r_{k t}$ is the real interest rate on capital in period $t$, which is known to the firm at the beginning of time $t$ and output $Y_{i t}$ is given by equation (2.6).

We decompose the information set of firm $i$ at the beginning of period $t, \Omega_{f, i t}$ into the common component, $\Psi_{t-1}$, and a private (or firm-specific) component $\Theta_{f, i t}$. For each firm $i$, namely $\Omega_{f, i t}=$ $\Psi_{t-1} \cup \Theta_{f, i t}$, where $\Theta_{f, i t}$ is given by

$$
\begin{aligned}
\Theta_{f, i t}= & \left\{\Lambda_{i t-1}, \Lambda_{i t-2}, \ldots ; Y_{i, t-1}, Y_{i, t-2}, \ldots ; K_{i t}, K_{i, t-1}, \ldots ;\right. \\
& \left.N_{i t}, N_{i, t-1}, \ldots ; L_{i t}, L_{i, t-1}, \ldots ; W_{t} ; r_{l t} ; r_{k t} ; v_{i}\right\} .
\end{aligned}
$$

The first-order conditions for firm $i$ 's optimization problem yield the optimal levels of capital and labour inputs and are given by

$$
\begin{aligned}
E\left[\alpha\left(\Lambda_{i t} A_{t}\right)^{\varphi}\left(\frac{N_{i t}}{K_{i t}}\right)^{1-\alpha} \mid \Omega_{f, i t}\right] & =1+r_{k t}, \\
E\left[(1-\alpha)\left(\Lambda_{i t} A_{t}\right)^{\varphi}\left(\frac{K_{i t}}{N_{i t}}\right)^{\alpha} \mid \Omega_{f, i t}\right] & =W_{t} .
\end{aligned}
$$

These equations state that the expected marginal products of capital and labour are equal to the return on capital and the wage rate, respectively.

Given the independence of $\lambda_{i t}$ and the innovation to $a_{t}$, we have

$$
E\left(\Lambda_{i t}^{\varphi} A_{t}^{\varphi} \mid \Omega_{f, i t}\right)=E\left(e^{\varphi \lambda_{i t}} \mid \Omega_{f, i t}\right) E\left(e^{\varphi a_{t}} \mid \Omega_{f, i t}\right) .
$$

We define the moment-generating functions of $\lambda$ and $\varepsilon$ by $M_{\lambda}(\varphi)=E\left(e^{\varphi \lambda_{i t}} \mid \Omega_{f, i t}\right)$ and $M_{\varepsilon}(\varphi)=$ $E\left(e^{\varphi \varepsilon_{t}} \mid \Omega_{f, i t}\right)$, respectively, assuming $M_{\lambda}(\varphi)$ and $M_{\varepsilon}(\varphi)$ exist. Using equations (2.10) and (2.14),

\footnotetext{
${ }^{6}$ The stochastic discount factor associated with the household utility function is given by $m_{t+s}=\beta^{s} \frac{U_{C}\left(C_{t+s}, N_{t+s}\right)}{U_{C}\left(C_{t}, N_{t}\right)}$.
} 
it can be shown that the optimal capital-to-labour ratio is identical for all firms, and is given by

$$
\frac{K_{i t}}{N_{i t}}=\left(\frac{\alpha M_{\lambda} M_{\varepsilon}}{1+r_{k t}}\right)^{\frac{1}{1-\alpha}} \exp \left[\frac{\varphi\left(a_{t-1}+\mu+\rho_{u} u_{t-1}\right)}{1-\alpha}\right], \quad \forall i,
$$

where we denote $M_{\lambda}=M_{\lambda}(\varphi)$ and $M_{\varepsilon}=M_{\varepsilon}(\varphi)$ to simplify the notation. Recall that we have assumed firms to be identical ex ante, that is, $N_{i t}$ and $K_{i t}$ are independent of $i$ and depend only on last period's technology shock, since $N_{i t}$ and $K_{i t}$ are chosen before the realization of this period's technology shock. In equilibrium we must have

$$
K_{i t}=K_{t}, N_{i t}=N_{t}, L_{i t}=L_{t}, v_{i}=v \quad \forall i,
$$

where $K_{t}=m^{-1} \Sigma_{i=1}^{m} K_{i t}, L_{t}=m^{-1} \Sigma_{i=1}^{m} L_{i t}$ and $N_{t}=m^{-1} \Sigma_{i=1}^{m} N_{i t}$.

To determine the optimal level of capital and labour, respectively, note that equation (2.5) in the household optimization problem and the ratio between the first-order conditions (2.14) and (2.15) imply that

$$
K_{t}=\frac{\alpha \chi_{0}}{1-\alpha} \cdot \frac{N_{t}^{1+\chi}}{1+r_{k t}}
$$

Using equations (2.16), (2.17) and (2.18), we also derive the following expression for optimal labour hours

$$
N_{t}=\left[\frac{1-\alpha}{\alpha \chi_{0}}\left(\alpha M_{\lambda} M_{\varepsilon}\right)^{\frac{1}{1-\alpha}}\left(1+r_{k t}\right)^{-\frac{\alpha}{1-\alpha}}\right]^{\frac{1}{\chi}} \exp \left[\frac{\varphi\left(a_{t-1}+\mu+\rho_{u} u_{t-1}\right)}{\chi(1-\alpha)}\right] .
$$

It is assumed that the rate of return on capital is identical to the rate of return on loans, $r_{k t}=r_{l t}$. A wedge can be introduced between the two rates of returns by introducing information asymmetries and monitoring costs. However, to keep the analysis simple and tractable, we abstract from these complications.

\subsubsection{Firms' default condition}

We allow for the possibility of firm defaults in our model economy. Firm $i$ is expected to default if the technology shock to the $i$ th firm is unfavorable, such that the value of the firm after wage payments, which we take as $Y_{i t}-W_{t} N_{i t}$ (since price is normalized to 1) falls below a threshold value determined by its callable liabilities, which we take as the repayment of loan $R_{l t} L_{i t}$, where $R_{l t}=1+r_{l t}$. See, for example, Merton (1974), and Pesaran, Schuermann, Treutler, and Weiner (2006). Our set up avoids the need for collateral or monitoring by banks since all firms are ex ante identical and the bank relies on the diversification of idiosyncratic shocks across firms as a form of insurance. The default condition is such that firm $i$ defaults if and only if

$$
Y_{i t}-W_{t} N_{i t}<R_{l t} L_{i t}
$$

To determine the probability of default, we first define $\zeta_{i t}=\lambda_{i t}+\varepsilon_{t}$, and note that, under our assumption, $\zeta_{i t} \sim \operatorname{iid}\left(0, \sigma_{\zeta}^{2}\right)$, where $\sigma_{\zeta}^{2}=\sigma_{\varepsilon}^{2}+\sigma_{\lambda}^{2}$, and $\zeta_{i t}$ has the following moment-generating function

$$
M_{\zeta}=M_{\zeta}(\varphi)=E\left(e^{\varphi \zeta_{i t}} \mid \Omega_{f, i t}\right)=M_{\lambda} M_{\varepsilon}
$$


Equations (2.5), (2.6), (2.12), (2.14), (2.17) and (2.18) imply that firm $i$ defaults if and only if

$$
\frac{e^{\varphi \zeta_{i t}}}{M_{\zeta}}-(1-\alpha)-\alpha\left(1-\frac{1}{v}\right)<0
$$

since $K_{i t}, 1+r_{l t}$ and $\alpha$ are positive. Alternatively, the default condition can be written as

$$
\zeta_{i t}<\frac{\ln \left(1-\frac{\alpha}{v}\right)+\ln M_{\zeta}}{\varphi} \equiv \varpi_{1}
$$

Let $d_{i t}$ denote the default indicator, defined as

$$
d_{i t}=I\left(\zeta_{i t}<\varpi_{1}\right)
$$

where $I(A)$ takes the value of unity if $A$ holds or zero otherwise. Default occurs if the combined technology shock (idiosyncratic and common) falls below a certain threshold $\varpi_{1}$, defined in (2.22), which is common to all firms.

The probability of default depends on the probability distribution of $\zeta_{i t}$. Under the assumption that the shocks are normally distributed, we have

$$
M_{\varepsilon}=\exp \left(\frac{\varphi^{2} \sigma_{\varepsilon}^{2}}{2}\right), \quad M_{\lambda}=\exp \left(\frac{\varphi^{2} \sigma_{\lambda}^{2}}{2}\right), \quad M_{\zeta}=\exp \left(\frac{\varphi^{2} \sigma_{\zeta}^{2}}{2}\right),
$$

and the default probability is given by

$$
\kappa=P\left(\zeta_{i t}<\varpi_{1} \mid \Omega_{f, i t}\right)=\Phi\left[\frac{\ln \left(1-\frac{\alpha}{v}\right)}{\varphi \sigma_{\zeta}}+\frac{\varphi \sigma_{\zeta}}{2}\right],
$$

where $\Phi(\cdot)$ is the cumulative distribution function of a standard normal. ${ }^{7}$ Under our assumptions, the probability of default $\kappa$ is time-invariant, but it is clear that time variation in $\kappa$ can be allowed for by introducing time variation in the volatility of technology shocks. This is in line with the recent literature by Bloom (2009). The economy-wide default probability depends on the following deep structural parameters in the model: $\alpha$, the share of capital; $v$, the leverage ratio of firms; $\varphi$, the exponent of technological process; and $\sigma_{\zeta}$, which depends on $\sigma_{\varepsilon}$ and $\sigma_{\lambda}$, the standard deviation of common and idiosyncratic technology shocks, respectively.

The partial derivatives of $\kappa$, with respect to the firm's leverage factor $v$ and the standard deviation of the combined technology shocks $\sigma_{\zeta}$ are given by

$$
\begin{aligned}
\frac{\partial \kappa}{\partial v} & =\frac{\alpha}{\varphi \sigma_{\zeta} v(v-\alpha)} \cdot \phi\left[\frac{\ln \left(1-\frac{\alpha}{v}\right)}{\varphi \sigma_{\zeta}}+\frac{\varphi \sigma_{\zeta}}{2}\right]>0 \\
\frac{\partial \kappa}{\partial \sigma_{\zeta}} & =\left[-\frac{\ln \left(1-\frac{\alpha}{v}\right)}{\varphi \sigma_{\zeta}^{2}}+\frac{\varphi}{2}\right] \cdot \phi\left[\frac{\ln \left(1-\frac{\alpha}{v}\right)}{\varphi \sigma_{\zeta}}+\frac{\varphi \sigma_{\zeta}}{2}\right]>0
\end{aligned}
$$

since the density function of a standard normal distribution, $\phi(\cdot)$, is positive, the firm's leverage factor $v$ is greater than or equal to 1 (and therefore $\alpha$ ), $\ln \left(1-\frac{\alpha}{v}\right)<0$ and the parameters $\alpha, \varphi$ and

\footnotetext{
${ }^{7}$ The moment-generating function of a random variable $X$ is defined as $M_{X}(t)=\mathbf{E}\left(e^{t X}\right), \quad t \in \mathbb{R}$, wherever this expectation exists. For a log-normal distribution where $\ln x \sim N\left(\mu, \sigma^{2}\right)$, all moments exist and $E(x)=e^{\mu+\frac{\sigma^{2}}{2}}$.
} 
$\sigma_{\zeta}$ are positive. Therefore, the default probability rises with $v$, as firms become more leveraged and more dependent on bank finance; and it rises with the volatility of combined technology shocks, $\sigma_{\zeta}$, as expected.

\subsubsection{Resource transfers and default settlements}

Two outcomes can arise after the realization of technology shocks.

Outcome 1: Firm $i$ does not default $\left(Y_{i t}-W_{t} N_{i t}-R_{l t} L_{i t} \geqslant 0\right)$. As we have shown earlier, $Y_{i t}-W_{t} N_{i t}-R_{l t} L_{i t} \geqslant 0$ if and only if $\zeta_{i t} \geqslant \varpi_{1}$, which occurs with a probability of $1-\kappa$. When firm $i$ does not default, the bank is repaid the principal and interest on the loan, $R_{l t} L_{i t}$, and the household receives a non-negative transfer from the firm after wage payment:

$$
\begin{array}{ll}
\Pi_{i, t c}=Y_{i t}-W_{t} N_{i t}-R_{l t} L_{i t} \geqslant 0, & \text { if firm } i \text { does not default, } \\
\Pi_{i, t b}=R_{l t} L_{i t}, & \text { if firm } i \text { does not default. }
\end{array}
$$

$\Pi_{i, t c}$ is the compensation the household receives for its equity investment in the non-defaulted firm $i$.

Outcome 2: Firm $i$ defaults $\left(Y_{i t}-W_{t} N_{i t}-R_{l t} L_{i t}<0\right)$. When firm $i$ defaults, it is unable to repay the loans, $R_{l t} L_{i t}$, to the banking sector. The bank instead seizes the revenue of the defaulted firm after wage payments, if this value $\left(Y_{i t}-W_{t} N_{i t}\right)$ is positive; otherwise, the bank gets no payment. The household bears the rest of default losses and receives a zero or negative transfer from the firm after wage payment. More specifically,

$$
\begin{aligned}
& \Pi_{i, t c}=\operatorname{Min}\left(0, Y_{i t}-W_{t} N_{i t}\right), \text { if firm } i \text { defaults, } \\
& \Pi_{i, t b}=\operatorname{Max}\left(0, Y_{i t}-W_{t} N_{i t}\right), \text { if firm } i \text { defaults. }
\end{aligned}
$$

Depending on the realization of technology shocks, there are two subcases resulting from Outcome 2 to distinguish. In the first sub-case, firm $i$ defaults and the transfer to the household is negative $\left(Y_{i t}-W_{t} N_{i t}<0\right)$.

Using equations (2.5), (2.6), (2.14), (2.17) and (2.18), we have the condition that $Y_{i t}-W_{t} N_{i t}<0$ if and only if

$$
\frac{e^{\varphi \zeta_{i t}}}{M_{\zeta}}-(1-\alpha)<0
$$

since $K_{i t}, R_{l t}$ and $\alpha$ are positive, which is given in logarithm by

$$
\zeta_{i t}<\frac{\ln (1-\alpha)}{\varphi}+\frac{\varphi \sigma_{\zeta}^{2}}{2} \equiv \varpi_{2}
$$

The probability $\tau$ that the household receives a negative transfer is therefore

$$
\tau=P\left(\zeta_{i t}<\varpi_{2} \mid \Omega_{f, i t}\right)=\Phi\left[\frac{\ln (1-\alpha)}{\varphi \sigma_{\zeta}}+\frac{\varphi \sigma_{\zeta}}{2}\right]
$$


which is independent of $i$ and $t$. The household and the bank receive a negative and zero transfer from the firms, respectively, where $\Pi_{i, t c}=Y_{i t}-W_{t} N_{i t}<0$ and $\Pi_{i, t b}=0$.

In the second sub-case, firm $i$ defaults and the revenue generated is sufficient to cover wage payments, $\left(0<Y_{i t}-W_{t} N_{i t}<R_{l t} L_{i t}\right)$. This scenario arises if and only if the combined technology shock, $\zeta_{i t}$, lies within the range given by $\varpi_{2}<\zeta_{i t}<\varpi_{1}$, with a probability of $\kappa-\tau$. The household receives zero transfer after the wage payment and the bank seizes the revenue of the defaulted firm after wage payments, where $\Pi_{i, t c}=0$ and $\Pi_{i, t b}=Y_{i t}-W_{t} N_{i t}>0$.

\subsubsection{Aggregation}

To study the equilibrium conditions of the aggregate model economy, we consider the cross-sectional average of firm output, defined by

$$
Y_{t}=\frac{\sum_{i=1}^{m} Y_{i t}}{m}=\left(\frac{\sum_{i=1}^{m} e^{\varphi \lambda_{i t}}}{m}\right) A_{t}^{\varphi} N_{t}^{1-\alpha} K_{t}^{\alpha}
$$

But since $\lambda_{i t}$ is assumed to be identically and independently distributed and $E\left(e^{\varphi \lambda_{i t}}\right)$ exists, then according to the law of large numbers we have

$$
\frac{\sum_{i=1}^{m} e^{\varphi \lambda_{i t}}}{m} \stackrel{p}{\rightarrow} E_{c}\left(e^{\varphi \lambda_{i t}}\right)=M_{\lambda}(\varphi)=M_{\lambda}
$$

where $E_{c}\left(e^{\varphi \lambda_{i t}}\right)$ is the cross-sectional expectation of $e^{\varphi \lambda_{i t}}$. Therefore, aggregate output is given by ${ }^{8}$

$$
Y_{t}=M_{\lambda} A_{t}^{\varphi} N_{t}^{1-\alpha} K_{t}^{\alpha}
$$

Recall that the household and banking sector receive a transfer from the firms after production, the amount of which depends on the realization of technology shocks. By denoting with $\Pi_{t c}$ the average transfer to the household and $\Pi_{t b}$ the average transfer to the banking sector, we have

$$
Y_{t}-W_{t} N_{t}=\Pi_{t c}+\Pi_{t b}
$$

where $\Pi_{t c}$ and $\Pi_{t b}$ comprise the payoffs from both defaulted and non-defaulted firms:

$$
\begin{aligned}
\Pi_{t c} & =\frac{\sum_{i=1}^{m}\left(1-d_{i t}\right)\left(Y_{i t}-W_{t} N_{i t}-R_{l t} L_{i t}\right)+\sum_{i=1}^{m} d_{i t} \operatorname{Min}\left(0, Y_{i t}-W_{t} N_{i t}\right)}{m}, \\
\Pi_{t b} & =\frac{\sum_{i=1}^{m} d_{i t} \operatorname{Max}\left(0, Y_{i t}-W_{t} N_{i t}\right)+\sum_{i=1}^{m}\left(1-d_{i t}\right) L_{i t} R_{l t}}{m} .
\end{aligned}
$$

We evaluate $\Pi_{t c}$ in equation (2.32) by first noting that $\operatorname{Min}\left(0, Y_{i t}-W_{t} N_{i t}\right)$ can be written in terms of the following indicator function:

$$
\begin{aligned}
& \operatorname{Min}\left(0, Y_{i t}-W_{t} N_{i t}\right) \\
= & I\left(\zeta_{i t}<\varpi_{2}\right) \cdot\left(Y_{i t}-W_{t} N_{i t}\right)+I\left(\varpi_{2}<\zeta_{i t}<\varpi_{1}\right) \cdot 0 .
\end{aligned}
$$

\footnotetext{
${ }^{8}$ It is relatively easy to allow $M_{\lambda}$ to be time-varying.
} 
Recall that $d_{i t}=I\left(\zeta_{i t}<\varpi_{1}\right)$, therefore

$$
d_{i t} \operatorname{Min}\left(0, Y_{i t}-W_{t} N_{i t}\right)=I\left(\zeta_{i t}<\varpi_{2}\right) \cdot\left(Y_{i t}-W_{t} N_{i t}\right) .
$$

According to the law of large numbers, for large $m$,

$$
\frac{\sum_{i=1}^{m} d_{i t}}{m} \stackrel{p}{\rightarrow} E_{c}\left(d_{i t}\right)=\kappa \quad \forall i \text { and } t,
$$

where $\kappa$ is the probability of default.

The average output of the defaulted firms can be expressed as

$$
\frac{\sum_{i=1}^{m} d_{i t} Y_{i t}}{m}=\frac{\sum_{i=1}^{m} d_{i t} e^{\varphi \lambda_{i t}}}{m} A_{t}^{\varphi} N_{t}^{1-\alpha} K_{t}^{\alpha}
$$

Note also $d_{i t}=I\left(\lambda_{i t}+\varepsilon_{t}<\varpi_{1}\right)=I\left(\lambda_{i t}<\varpi_{1}-\varepsilon_{t}\right)$. According to the law of large numbers,

$$
\frac{\sum_{i=1}^{m} e^{\varphi \lambda_{i t}} I\left(\lambda_{i t}<\varpi_{1}-\varepsilon_{t}\right)}{m} \stackrel{p}{\rightarrow} \int_{-\infty}^{\varpi_{1}-\varepsilon_{t}} e^{\varphi x} f_{\lambda}(x) d x, \text { as } m \rightarrow \infty,
$$

where $f_{\lambda}(x)$ is the probability density function of $\lambda_{i t}$.

Lemma 1 In the case where $\lambda_{i t} / \sigma_{\lambda} \sim N(0,1)$, and hence $f_{\lambda}(x)=\phi\left(x / \sigma_{\lambda}\right)$ is the normal density, we have

$$
\int_{-\infty}^{\varpi_{1}-\varepsilon_{t}} e^{\varphi x} f_{\lambda}(x) d x=M_{\lambda} \varsigma_{1}\left(\varepsilon_{t}\right)
$$

where $M_{\lambda}$ is given by (2.24) and

$$
\varsigma_{1}\left(\varepsilon_{t}\right)=\Phi\left(\frac{\varpi_{1}-\varepsilon_{t}-\sigma_{\lambda}^{2} \varphi}{\sigma_{\lambda}}\right)
$$

Proof. See Appendix A1.

Following from Lemma 1, for large $m$,

$$
\frac{\sum_{i=1}^{m} d_{i t} Y_{i t}}{m} \stackrel{p}{\rightarrow} M_{\lambda} \varsigma_{1}\left(\varepsilon_{t}\right) A_{t}^{\varphi} N_{t}^{1-\alpha} K_{t}^{\alpha}=\varsigma_{1}\left(\varepsilon_{t}\right) Y_{t}
$$

Finally, using the law of large numbers and Lemma 1, it can be shown that

$$
\begin{array}{rll}
\frac{\sum_{i=1}^{m} I\left(\zeta_{i t}<\varpi_{2}\right)}{m} & \stackrel{p}{\rightarrow} \tau, \\
\frac{\sum_{i=1}^{m} I\left(\lambda_{i t}<\varpi_{2}-\varepsilon_{t}\right) Y_{i t}}{m} & \stackrel{p}{\rightarrow} \varsigma_{2}\left(\varepsilon_{t}\right) Y_{t},
\end{array}
$$

where $\tau$ is given by (2.29) and

$$
\varsigma_{2}\left(\varepsilon_{t}\right)=\Phi\left(\frac{\varpi_{2}-\varepsilon_{t}-\sigma_{\lambda}^{2} \varphi}{\sigma_{\lambda}}\right)
$$

The transfer of resources from firms to the household sector, $\Pi_{t c}$, and the banking sector, $\Pi_{t b}$, 
are therefore given by

$$
\begin{aligned}
\Pi_{t c} & =\left[1-\varsigma_{1}\left(\varepsilon_{t}\right)\right] Y_{t}-\left(W_{t} N_{t}+R_{l t} L_{t}\right)(1-\kappa)+\varsigma_{2}\left(\varepsilon_{t}\right) Y_{t}-\tau W_{t} N_{t}, \\
\Pi_{t b} & =R_{l t} L_{t}(1-\kappa)-(\kappa-\tau) W_{t} N_{t}+\left[\varsigma_{1}\left(\varepsilon_{t}\right)-\varsigma_{2}\left(\varepsilon_{t}\right)\right] Y_{t},
\end{aligned}
$$

where $Y_{t}, \kappa, \varsigma_{1}\left(\varepsilon_{t}\right)$ and $\varsigma_{2}\left(\varepsilon_{t}\right)$ are given in (2.30), (2.25), (2.34) and (2.35), respectively.

\subsection{The banking sector}

The banking sector acts as the financial intermediary between the household and the firms. It receives deposits, $D_{t}$, from the household at the beginning of time $t$ and channels these deposits to loans, $L_{t}$, extended to the firms. We postulate the relationship between $L_{t}$ and $D_{t}$ as

$$
L_{t}=\theta_{t} D_{t},
$$

where $\theta_{t}$ is assumed to be exogenously given. Equation (2.38) allows us to introduce shocks that originate on the supply side of credit and to study their propagation in the real economy, in a tractable manner.

One interpretation of (2.38) is that the banking sector is required to deposit some reserves, $B_{t}$, with the central bank, through which the central bank is able to influence the amount of bank credit available in the economy (see, for example, the bank balance sheet in Freixas and Rochet, 2008). In this case, $L_{t}+B_{t}=D_{t}$, where $B_{t}=\left(1-\theta_{t}\right) D_{t}$. The purpose of a compulsory reserve requirement as a policy instrument can be twofold. When the economy is overheating and the level of fixed investment is high, the central bank can raise the reserve-requirement ratio $\left(1-\theta_{t}\right)$, to curb credit expansion and reduce the inflationary pressure in the economy, in which case the reserve requirement acts as a countercyclical policy tool. Alternatively, when lending risk is high (for example, owing to an increase in firm default probability), the central bank may raise the reserve-requirement ratio to ensure that the banking sector puts aside sufficient reserves to cushion the impact of higher bank losses due to firm defaults. Further, $\theta_{t}$ can be interpreted as a macroprudential policy tool, where the financial regulatory authority targets the volume of loans extended to the real economy, to dampen procyclicality in the credit cycle. In both cases, $\theta_{t}$ will be less than 1 .

However, one could also consider the case where $\theta_{t}$ is greater than 1 . This is possible when banks are allowed to issue securities (IOUs) that are not backed by deposits. These securities could potentially be guaranteed by the central bank in event of a bank run (not modeled in our framework). The central bank can also be a source of additional liquidity to the banking sector, as seen in the recent financial crisis. To model this possibility explicitly, one would need to introduce the price level and inflation into our framework, since the central bank's credit provision could lead to inflationary pressure in the economy. Given the relatively simple and canonical characterization of the banking sector in our model, we abstract from pinpointing the exact source of the credit shock; instead, we investigate all three different scenarios where the mean of $\theta_{t}$, denoted by $\mu_{\theta}$ below, is less than, equal to and greater than unity in our calibration and simulation exercises.

For the banking sector to be solvent, the following condition must be satisfied: the end-ofperiod asset position of the banking sector must be greater than or equal to the liabilities of the 
banking sector. Assume that the banking sector makes zero profit and, in equilibrium, we have

$$
\left(1+r_{d t}\right) D_{t}=\Pi_{t b}
$$

where $\Pi_{t b}$, the transfer from firms comprising loan repayments from solvent firms and the confiscation of assets of defaulted firms, is given by equation (2.37).

The exogenous process for the loan-to-deposit ratio, $\theta_{t}$, is assumed to follow

$$
\ln \theta_{t}=\rho_{\theta} \ln \theta_{t-1}+\eta_{t},
$$

where $\left|\rho_{\theta}\right|<1$, and $\eta_{t} \sim N\left(\mu_{\eta}, \sigma_{\eta}^{2}\right)$. The distribution of $\ln \theta_{t}$ is therefore given by $\ln \theta_{t} \sim$ $N\left(\frac{\mu_{\eta}}{1-\rho_{\theta}}, \frac{\sigma_{\eta}^{2}}{1-\rho_{\theta}^{2}}\right)$. Using the properties of the log-normal distribution, we have

$$
E\left(\theta_{t}\right)=E\left(e^{\ln \theta_{t}}\right)=\exp \left(\frac{\mu_{\eta}}{1-\rho_{\theta}}+\frac{1}{2} \frac{\sigma_{\eta}^{2}}{1-\rho_{\theta}^{2}}\right)=\mu_{\theta},
$$

where $\mu_{\theta}$ is the mean of the loan-to-deposit ratio. $\mu_{\eta}$ and $E\left(\ln \theta_{t}\right)$ can be expressed in terms of $\mu_{\theta}$, $\sigma_{\eta}$ and $\rho_{\theta}$, as follows

$$
\begin{aligned}
\mu_{\eta} & =\left(1-\rho_{\theta}\right) \ln \left(\mu_{\theta}\right)-\frac{1}{2} \frac{\sigma_{\eta}^{2}}{1+\rho_{\theta}} \\
E\left(\ln \theta_{t}\right) & =\ln \left(\mu_{\theta}\right)-\frac{1}{2} \frac{\sigma_{\eta}^{2}}{1-\rho_{\theta}^{2}} .
\end{aligned}
$$

Finally, for completeness, the information set for the bank $\Omega_{b t}$ can be written as $\Omega_{b t}=\Psi_{t-1} \cup$ $\Theta_{b t}$, where $\Theta_{b t}$ contains information that is known to the bank at the beginning of time $t$ and $\Theta_{b t}=\left\{\Pi_{t b}, \Pi_{t-1, b}, \ldots ; r_{d t} ; r_{l t} ; L_{t} ; D_{t} ; \theta_{t}\right\}$. As in Binder and Pesaran $(1998,2001), \Psi_{t-1}$ is a common information set, containing all the publicly available information at the beginning of period $t$ that is common to the household, firms and the bank:

$$
\begin{aligned}
\Psi_{t-1}= & \left\{C_{t-1}, C_{t-2}, \ldots ; K_{t-1}, K_{t-2}, \ldots ; Y_{t-1}, Y_{t-2}, \ldots ; L_{t-1}, L_{t-2}, \ldots ; D_{t-1}, D_{t-2}, \ldots ;\right. \\
& N_{t-1}, N_{t-2}, \ldots ; W_{t-1}, W_{t-2}, \ldots ; r_{d, t-1}, r_{d, t-2}, \ldots ; r_{l, t-1}, r_{l, t-2}, \ldots ; \varepsilon_{t-1}, \varepsilon_{t-2,} \ldots \\
& \left.\theta_{t-1}, \theta_{t-2}, \ldots\right\}
\end{aligned}
$$

\section{Short-Run Equilibrium Conditions and Long-Run Steady States}

\subsection{Equilibrium conditions}

The complete set of equations that characterize the equilibrium conditions of the model is given by equations $(2.2),(2.4),(2.5),(2.18),(2.19),(2.30),(2.31),(2.37),(2.38),(2.39)$ and the aggregate version of equations (2.11) and (2.12). We set out below the key equations of the complete macroeconomic framework again for convenience: 


$$
\begin{aligned}
1 & =E\left[\beta\left(\frac{C_{t+1}-\frac{\chi_{0}}{1+\chi} N_{t+1}^{1+\chi}}{C_{t}-\frac{\chi_{0}}{1+\chi} N_{t}^{1+\chi}}\right)^{-\gamma} R_{d, t+1} \mid \Omega_{c t}\right] \\
W_{t} & =\chi_{0} N_{t}^{\chi} \\
D_{t+1} & =R_{d t} D_{t}+W_{t} N_{t}-C_{t}-S_{t}+\Pi_{t c} \\
K_{t} & =\frac{\alpha \chi_{0}}{1-\alpha} \cdot \frac{N_{t}^{1+\chi}}{R_{l t}} \\
N_{t} & =\left[\frac{1-\alpha}{\alpha \chi_{0}}\left(\alpha M_{\lambda} M_{\varepsilon}\right)^{\frac{1}{1-\alpha}}\right]^{\frac{1}{\chi}}\left(R_{l t}\right)^{-\frac{\alpha}{(1-\alpha) \chi}} \exp \left[\frac{\varphi\left(a_{t-1}+\mu+\rho_{u} u_{t-1}\right)}{\chi(1-\alpha)}\right], \\
Y_{t} & =M_{\lambda} A_{t}^{\varphi} N_{t}^{1-\alpha} K_{t}^{\alpha}, \\
L_{t} & =\left(1-\frac{1}{v}\right) K_{t}, \\
\Pi_{t b} & =R_{d t} D_{t} \\
K_{t} & =L_{t}+S_{t} \\
L_{t} & =\theta_{t} D_{t} \\
\Pi_{t b} & =R_{l t} L_{t}(1-\kappa)-(\kappa-\tau) W_{t} N_{t}+\varsigma\left(\varepsilon_{t}\right) Y_{t}, \\
\Pi_{t c} & =Y_{t}-W_{t} N_{t}-\Pi_{t b},
\end{aligned}
$$

where

$$
\begin{aligned}
\kappa & =\Phi\left(\frac{\varpi_{1}}{\sigma_{\zeta}}\right), \tau=\Phi\left(\frac{\varpi_{2}}{\sigma_{\zeta}}\right), \quad \varsigma\left(\varepsilon_{t}\right)=\varsigma_{1}\left(\varepsilon_{t}\right)-\varsigma_{2}\left(\varepsilon_{t}\right), \\
\varsigma_{1}\left(\varepsilon_{t}\right) & =\Phi\left(\frac{\varpi_{1}-\varepsilon_{t}-\sigma_{\lambda}^{2} \varphi}{\sigma_{\lambda}}\right), \quad \varsigma_{2}\left(\varepsilon_{t}\right)=\Phi\left(\frac{\varpi_{2}-\varepsilon_{t}-\sigma_{\lambda}^{2} \varphi}{\sigma_{\lambda}}\right), \\
\varpi_{1} & =\frac{\ln \left(1-\frac{\alpha}{v}\right)}{\varphi}+\frac{\varphi \sigma_{\zeta}^{2}}{2}, \quad \varpi_{2}=\frac{\ln (1-\alpha)}{\varphi}+\frac{\varphi \sigma_{\zeta}^{2}}{2}, \\
M_{\lambda} & =\exp \left(\frac{\varphi^{2} \sigma_{\lambda}^{2}}{2}\right), \quad M_{\epsilon}=\exp \left(\frac{\varphi^{2} \sigma_{\epsilon}^{2}}{2}\right), \\
R_{l t} & =1+r_{l t} \text { and } R_{d t}=1+r_{d t} .
\end{aligned}
$$

There are 12 equations governing the macroeconomy, (3.1) to (3.12), in 12 endogenous variables $C_{t}, W_{t}, N_{t}, D_{t}, S_{t}, L_{t}, K_{t}, Y_{t}, \Pi_{t b}, \Pi_{t c}, R_{d t}$ and $R_{l t}$. The model is subject to two exogenously determined processes, the technological process, $a_{t}$, and the credit shock to $\theta_{t}$, governed by

$$
\begin{aligned}
a_{t} & =a_{t-1}+\mu+u_{t}, \quad \text { where } u_{t}=\rho_{u} u_{t-1}+\varepsilon_{t}, \\
\ln \theta_{t} & =\rho_{\theta} \ln \theta_{t-1}+\eta_{t} .
\end{aligned}
$$

We combine equations (3.3), (3.8) and (3.12) to obtain the economy-wide budget constraint in our model

$$
Y_{t}-C_{t}=S_{t}+D_{t+1}
$$

which shows that the composition of output net of consumption (savings) is in the form of "privateequity' investment, $S_{t}$, and deposits, $D_{t+1}$.

From simulation exercises, we find that $\varsigma\left(\varepsilon_{t}\right)$ is very small for reasonable parameter values of 
$\alpha, v, \chi, \sigma_{\varepsilon}^{2}$ and $\sigma_{\lambda}^{2}$. As a result, we approximate equation (3.11) with the following expression ${ }^{9}$ :

$$
\Pi_{t b}=R_{l t} L_{t}(1-\kappa)-(\kappa-\tau) W_{t} N_{t} .
$$

We assume that a central planner with a common information set, $\Omega_{t}$, solves the system of equilibrium conditions. The common information set, $\Omega_{t}$, which is known to the planner at time $t$ is defined by

$$
\Omega_{t}=\Psi_{t-1} \cup \Theta_{b t} \cup \Theta_{c t} \cup\left(\cup_{i=1}^{m} \Theta_{f, i t}\right) .
$$

Note that the variables $C_{t}, D_{t+1}, L_{t}, K_{t}, S_{t}, N_{t}, W_{t}, R_{d t}, R_{l t}, Y_{t}, \Pi_{t c}, \Pi_{t b}, v, \theta_{t}$ and $\varepsilon_{t}$ are included in the planner's information set $\Omega_{t}$ at time $t$.

\subsection{Derivation of steady states}

Since this model depicts a growing economy where the technological process, $a_{t}$, contains a unit root as well as a deterministic growth component, $\mu$, we must scale the endogenous variables $C_{t}$, $L_{t}, D_{t}, S_{t}, K_{t}, W_{t}, N_{t}$ and $Y_{t}$ in the system of equilibrium conditions by an appropriate factor of technology, $A_{t-1}$, so that the transformed variables are stationary on a balanced growth path, to guarantee that the model possesses steady states. We shall also assume that the real interest rates are stochastically bounded (bounded in probability), that is, $R_{l t}=O_{p}(1)$ and $R_{d t}=O_{p}(1)$, which is in line with the empirical evidence on U.S. real interest rates series. ${ }^{10}$

Proposition 1 To guarantee the existence of steady states in the economy defined by equations (3.1) to (3.12), and the processes of the exogenous variables given in equations (3.13) and (3.14), the exponent of the technology process, $Z_{i t}$, in the firm's production function (2.6) must be restricted $a s$

$$
\varphi=\frac{(1-\alpha) \chi}{1+\chi}
$$

Proof. First note that (3.5) can be rewritten as

$$
N_{t}=\left[\frac{1-\alpha}{\alpha \chi_{0}}\left(\alpha M_{\lambda} M_{\varepsilon}\right)^{\frac{1}{1-\alpha}}\right]^{\frac{1}{\chi}}\left(R_{l t}\right)^{-\frac{\alpha}{(1-\alpha) \chi}}\left[A_{t-1}^{\frac{\varphi}{(1-\alpha) \chi}}\right] \exp \left[\frac{\varphi\left(\mu+\rho_{u} u_{t-1}\right)}{\chi(1-\alpha)}\right] .
$$

Assuming that real interest rates are bounded in probability and $u_{t}$ is stationary, we have

$$
N_{t}=O_{p}\left[A_{t-1}^{\frac{\varphi}{(1-\alpha) \chi}}\right]
$$

If we scale $K_{t}$ by $A_{t-1}$, equation (3.4) becomes

$$
\frac{K_{t}}{A_{t-1}}=\left(\frac{\alpha \chi_{0}}{1-\alpha}\right) \frac{N_{t}^{1+\chi} A_{t-1}^{-1}}{R_{l t}}
$$

\footnotetext{
${ }^{9}$ Under the baseline parametrization of the model, the average value of $\varsigma\left(\varepsilon_{t}\right)$ is very small, at 0.0062 for 100,000 simulations.

10 "Boundedness in probability" is defined as follows: the sequence $X_{n}$ is bounded in probability, written $X_{n}=$ $O_{p}(1)$, if for every $\varepsilon>0$ there exists $\delta(\varepsilon) \in(0, \infty)$ such that $\operatorname{Pr}\left[\left|X_{n}\right|>\delta(\varepsilon)\right]<\varepsilon$ for all n.
} 
Therefore, to ensure that $\frac{K_{t}}{A_{t-1}}$ is bounded in probability, (3.19) implies that

$$
N_{t}=O_{p}\left(A_{t-1}^{\frac{1}{1+\chi}}\right)
$$

But, for the results of (3.18) and (3.20) to be compatible, we must have the condition $\frac{\varphi}{(1-\alpha) \chi}=\frac{1}{1+\chi}$ or $\varphi=\frac{(1-\alpha) \chi}{1+\chi}$, as required.

Remark 1 The expressions for the endogenous variables (except for the interest rates) in efficiency units are given by $\stackrel{\circ}{C}_{t}=\frac{C_{t}}{A_{t-1}}, \stackrel{\circ}{L}_{t}=\frac{L_{t}}{A_{t-1}}, \stackrel{\circ}{S}_{t}=\frac{S_{t}}{A_{t-1}}, \stackrel{\circ}{D}_{t}=\frac{D_{t}}{A_{t-1}}, \stackrel{\circ}{K}_{t}=\frac{K_{t}}{A_{t-1}}, \stackrel{\circ}{W}_{t}=\frac{W_{t}}{A_{t-1}^{\chi \chi(1+\chi)}}$, $\stackrel{\circ}{N}_{t}=\frac{N_{t}}{A_{t-1}^{1 /(1+\chi)}}$ and $\stackrel{\circ}{Y}_{t}=\frac{Y_{t}}{A_{t-1}}$. In particular, equation (3.2) implies $W_{t}=\chi_{0} N_{t}^{\chi}=O_{p}\left(A_{t-1}^{\frac{\chi}{1+\chi}}\right)$, which implies that $W_{t}$ must be scaled by $A_{t-1}^{\frac{\chi}{1+\chi}}$, to ensure that $\stackrel{\circ}{W}_{t}$ is $O_{p}(1)$.

The growth rate of technology is given by

$$
g_{t}=\frac{e^{a_{t}}}{e^{a_{t-1}}}=e^{\mu+u_{t}}=(1+g) e^{u_{t}},
$$

where $u_{t}=\rho u_{t-1}+\varepsilon_{t}$, and $e^{\mu} \equiv 1+g$. In what follows, we denote the natural logarithm of variables with lowercase letters, that is $\stackrel{\circ}{c}_{t}=\ln \stackrel{\circ}{C}_{t}$, and denote the steady state of variables with lowercase letters with an asterisk, $\stackrel{c}{*}^{*}$.

When deriving the steady state, standard macro models set the shocks equal to zero and, in effect, abstract from any possible non-linearities in the steady state relations of the model. One limitation of the standard first-order perturbation approach is that the solution displays the certainty equivalence property, where the first-order approximation to the unconditional means of endogenous variables coincides with their non-stochastic, steady-state values, and therefore, by construction, rules out a risk premium in the steady state (Schmitt-Grohe and Uribe, 2004). Here we propose an alternative method where the steady-state relations of the model are derived from unconditional expectations of the model's relations in terms of the log of the variables measured in efficiency units. In our solution approach, the steady state of log consumption in efficiency units is defined as $\stackrel{\circ}{c}^{*}=E\left(\ln \stackrel{\bullet}{C}_{t}\right)$, and the steady-state loan rate is given by $r_{l}^{*}=E\left(\ln R_{l t}\right) \approx E\left(r_{l t}\right)$, which differ from the standard first-order perturbation approach in two aspects. First, we define steady states as the unconditional expectation of the $\log$ of the variables in efficiency units, rather than the variables themselves. Owing to the non-linear nature of the log operator, certainty equivalence no longer applies in the model solution, which allows us to study the role of the risk premium explicitly. Second, we consider in efficiency units all variables (except for interest rates), scaled by technology shocks, so that the transformed variables are ergodic, despite the presence of a unit root in the technology process. Using this approach and the properties of the log normal distribution, we are able to express the steady state of shocks as a function of their mean and standard deviation, therefore allowing for explicit consideration of risks in the steady state, without using second- or higher-order perturbation methods (see, for example, Schmitt-Grohe and Uribe, 2004 and Devereux and Sutherland, 2011). 
The steady state of the system of equilibrium conditions is therefore given by ${ }^{11}$

$$
\begin{aligned}
& E\left(\ln \theta_{t}\right)+\ddot{d}^{*}=\ln \chi_{0}+\ln \left[\frac{\alpha\left(1-\frac{1}{v}\right)}{1-\alpha}\right]+(1+\chi) \grave{n}^{*}-r_{l}^{*}, \\
& \stackrel{\circ}{n}^{*}=-\frac{\ln \chi_{0}}{\chi}+\frac{1}{\chi} \ln \left[\frac{1-\alpha}{\alpha}\left(\alpha M_{\lambda} M_{\varepsilon}\right)^{\frac{1}{1-\alpha}}\right]+\frac{\mu}{1+\chi}-\frac{\alpha}{(1-\alpha) \chi} r_{l}^{*}, \\
& \dot{y}^{*}=\ln \left[\frac{M_{\lambda}}{\left(1-\frac{1}{v}\right)^{\alpha}}\right]+\varphi \mu+(1-\alpha) \stackrel{n}{*}^{*} \alpha E\left(\ln \theta_{t}\right)+\alpha \dot{d}^{*} \text {, } \\
& e^{\hat{\vartheta}^{*}}-e^{\check{c}^{*}}=e^{\dot{d}^{*}+\mu}+\frac{1}{v-1} e^{E\left(\ln \theta_{t}\right)+\dot{d}^{*}}, \\
& r_{d}^{*}=\gamma \mu-\ln \beta, \\
& e^{r_{d}^{*}+\AA^{*}}=e^{r_{l}^{*}+E\left(\ln \theta_{t}\right)+\dot{d}^{*}}(1-\kappa)-\chi_{0}(\kappa-\tau) e^{(1+\chi) \hat{n}^{*}},
\end{aligned}
$$

where $\alpha, v, \chi, \mu, \gamma, \beta$ and $\chi_{0}$ are parameters of the model, which will be calibrated at a later stage. $M_{\lambda}$ and $M_{\varepsilon}$ are defined in (2.24), $\kappa$ and $\tau$ are given by equations (2.25) and (2.29), respectively, $E\left(\ln \theta_{t}\right)$ is given by equation (2.42), and $\varphi$ must satisfy equation (3.16) in Proposition 1.

\subsection{Log-liberalization}

Consistent with the above derivation of steady states, we log-linearize the system of equilibrium equations around the log steady state values obtained by solving (3.22) to (3.27). We denote the $\log$ deviations from the steady state as $\widetilde{\stackrel{\circ}{c}}_{t}=\stackrel{\circ}{c}_{t}-\stackrel{\circ}{c}^{*}$, where $\stackrel{\circ}{c}_{t}=\ln \stackrel{\overbrace{C}}{t}$, then

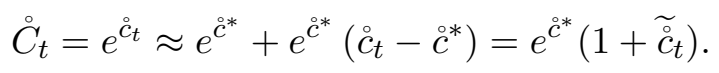

Also $\widetilde{\ln g_{t}}=\ln g_{t}-E\left(\ln g_{t}\right)$, where using (3.21) we have $\ln g_{t}=\mu+u_{t}$. Hence, $\widetilde{\ln g_{t}}=u_{t}=$ $\rho_{u} u_{t-1}+\varepsilon_{t}$. Similarly, for the logarithm of the loan-to-deposit ratio, $\widetilde{\ln \theta_{t}}=\ln \theta_{t}-E\left(\ln \theta_{t}\right)$, and since $\ln \theta_{t}=\rho_{\theta} \ln \theta_{t-1}+\eta_{t}$, then $\widetilde{\ln \theta_{t}}=\rho_{\theta} \widetilde{\ln \theta_{t-1}}+\widetilde{\eta}_{t}$, where $\widetilde{\eta}_{t}=\eta_{t}-\left(1-\rho_{\theta}\right) E\left(\ln \theta_{t}\right)$. However, using (2.42), and recalling that by assumption $\widetilde{\eta}_{t} \sim \mathbb{N}\left(\mu_{\eta}, \sigma_{\eta}^{2}\right)$, it then follows readily that, $\widetilde{\eta}_{t} \sim \mathbb{N}\left(0, \sigma_{\eta}^{2}\right)$.

The log-linearized approximation of the equilibrium conditions of the model are therefore given by $^{12}$

$$
\begin{aligned}
& \widetilde{\grave{c}}_{t}-a_{1} \widetilde{\tilde{n}}_{t}=E\left(\widetilde{\grave{c}}_{t+1}-a_{1}{\widetilde{\tilde{n}_{t+1}}}_{t}-a_{3} \widetilde{r}_{d, t+1} \mid \Omega_{c t}\right)+a_{2} u_{t}, \\
& -\widetilde{\tilde{c}}_{t}+\left(1+a_{4}+a_{6}\right) \widetilde{\tilde{y}}_{t}-a_{6} \widetilde{\stackrel{d}{d}}_{t+1}=a_{4} \widetilde{\stackrel{d}{d}}_{t}+a_{6} u_{t}+a_{4} \widetilde{\ln \theta} t \\
& \widetilde{\tilde{n}}_{t}+\frac{\alpha}{(1-\alpha) \chi} \widetilde{r}_{l t}=\frac{\rho_{u}}{1+\chi} u_{t-1}, \\
& \widetilde{r}_{d t}-\widetilde{r}_{l t}=\widetilde{\ln \theta_{t}}, \\
& \widetilde{\stackrel{y}{y}}_{t}-(1+\alpha \chi) \widetilde{\stackrel{n}{n}}_{t}+\alpha \widetilde{r}_{l t}=\varphi u_{t} \text {, } \\
& (1+\chi) \widetilde{\tilde{n}}_{t}-\widetilde{r}_{l t}=\widetilde{\stackrel{o}{d}}_{t}+\widetilde{\ln \theta_{t}},
\end{aligned}
$$

\footnotetext{
${ }^{11}$ The detailed derivation of the steady-state conditions can be found in Appendix A2.

${ }^{12}$ Note that $E\left(u_{t} \mid \Omega_{c t}\right)=u_{t}$. The derivation of the log-linearized approximation of the equilibrium conditions can be found in Appendix A2.
} 
where

$$
\begin{aligned}
& a_{1}=b_{1}(1+\chi), a_{2}=1-b_{1}, a_{3}=\frac{1-b_{1}}{\gamma}, \\
& a_{4}=\frac{1}{v-1} e^{E\left(\ln \theta_{t}\right)+\dot{d}^{*}-\dot{c}^{*}}, a_{6}=e^{\dot{d}^{*}+\mu-\dot{c}^{*}}, b_{1}=\frac{\chi_{0}}{1+\chi} e^{(1+\chi) \hat{n}^{*}-\dot{c}^{*}} .
\end{aligned}
$$

There are six equations as set out in (3.28) to (3.33) for six endogenous variables, $\widetilde{c}_{t}, \widetilde{\stackrel{d}{d}}_{t}, \widetilde{\stackrel{d}{y}}_{t}, \widetilde{\stackrel{n}{n}}_{t}$, $\widetilde{r}_{d t}$ and $\widetilde{r}_{l t}$, which are all known to the planner at time $t$.

\subsection{Impulse responses}

In our simulation exercises, we are interested in the impact of a positive credit shock on businesscycle dynamics. We compute the impulse responses to a credit shock following Koop, Pesaran, and Potter (1996) and Pesaran and Shin (1998), since the generalized impulse response functions offer more modelling flexibility.

Proposition 2 Under the system of equilibrium conditions set out in equations (3.28) to (3.33), it follows that:

(a) A credit shock has a negative impact on the interest rate spread, $\widetilde{r}_{l t}-\widetilde{r}_{d t}$.

(b) The level of labour hours and the loan rate respond in opposite directions following a credit shock.

Proof. The impulse responses implied by equations (3.30) and (3.31) can be written as

$$
\begin{aligned}
G I_{n}(h)+\frac{\alpha}{(1-\alpha) \chi} G I_{r_{l}}(h) & =\frac{\rho_{u}}{1+\chi} G I_{u}(h-1), \\
G I_{r_{d}}(h)-G I_{r_{l}}(h) & =G I_{l n \theta}(h),
\end{aligned}
$$

Result (a) follows from equation (3.35), which shows that the impulse response of the interest rate spread depends on the credit shock, and that a credit shock has a negative impact on the interest rate spread. Result (b) follows from equation (3.34), where $G I_{n}(h)+\frac{\alpha}{(1-\alpha) \chi} G I_{r_{l}}(h)=0$, following a credit shock.

\section{Parameter Calibration}

Following much of the literature, the capital share, $\alpha$, is set to 0.35 , the discount rate $r$ to 1.6 per cent per annum (0.4 per cent per quarter), which gives $\beta=0.996$. Following Greenwood, Hercowitz, and Huffman (1988), Christiano, Eichenbaum, and Evans (1997), and as is standard in business-cycle analysis, the coefficient of risk aversion, $\gamma$, is set to 1 . For $1 / \chi$, the intertemporal elasticity of substitution in labour supply, Greenwood, Hercowitz, and Huffman (1988) argue that, for a representative household, $1 / \chi$ should summarize the variation in labour of all members of such a unit, both at the intensive and extensive margins. These authors suggest that a reasonable value of $1 / \chi$ should lie in the range of 0.3 to 2.2 . In our calibrated exercise, we select a mid-point value in this range and set $1 / \chi=1.4$, or $\chi=0.7$. The scaling parameter, $\chi_{0}$, in $(2.3)$ is chosen so that the steady-state value of labour hours in efficiency units is set to unity, namely $\stackrel{\circ}{*}^{*}=e^{\mathfrak{n}^{*}}=1$. 
Table 1: Model Parameters

\begin{tabular}{|c|c|c|c|}
\hline \multicolumn{2}{|c|}{ Preference } & \multirow{2}{*}{$\begin{array}{l}\text { Value } \\
1\end{array}$} & \multirow{2}{*}{$\begin{array}{l}\text { Source } \\
\text { Christiano et al. (1997) }\end{array}$} \\
\hline$\gamma$ & coefficient of risk aversion & & \\
\hline$\chi$ & $\begin{array}{l}\text { inverse of the intertemporal elasticity of } \\
\text { substitution in labour supply }\end{array}$ & 0.7 & Greenwood et al. (1988) \\
\hline$\beta$ & discount factor & 0.996 & \\
\hline \multicolumn{4}{|c|}{ Technology } \\
\hline$\rho_{u}$ & $\begin{array}{l}\text { coefficient of autoregression in a common } \\
\text { technology shock }\end{array}$ & 0.439 & U.S. data \\
\hline$\sigma_{\varepsilon}$ & $\begin{array}{l}\text { standard deviation of a common } \\
\text { technology shock }\end{array}$ & 0.011 & U.S. data \\
\hline$\mu$ & deterministic trend in technology growth & 0.003 & U.S. data \\
\hline \multicolumn{4}{|c|}{ Production and firm financing } \\
\hline$\alpha$ & share of capital & 0.35 & BGG \\
\hline$v$ & firm's leverage factor & 1.43 & U.S. data \\
\hline$\kappa$ & probability of default & 0.086 & Moody's (2012) and BGG \\
\hline \multicolumn{4}{|c|}{ Credit } \\
\hline$\rho_{\theta}$ & $\begin{array}{l}\text { coefficient of autoregression in } \\
\text { a credit shock }\end{array}$ & 0.848 & U.S. data \\
\hline$\sigma_{\eta}$ & standard deviation of a credit shock & 0.011 & U.S. data \\
\hline$\mu_{\theta}$ & mean of loan-to-deposit ratio & $0.95,1,1.05$ & \\
\hline
\end{tabular}

The remaining parameters, $\rho_{u}, \sigma_{\varepsilon}, \mu, v, \rho_{\theta}, \sigma_{\eta}$ and $\sigma_{\lambda}$ are calibrated using U.S. quarterly time series data covering the period 1985Q1 to 2009Q4. ${ }^{13}$ Following the literature, we use the HodrickPrescott (1997) filter to extract the cyclical components from the data series, with a smoothing parameter value of 1600 , which is recommended for quarterly data. ${ }^{14}$ To derive the standard deviation of common technology shock, $\sigma_{\varepsilon}$, from U.S. data, we first detrend the log of the per capita real output series. The standard deviation of the cyclical component (as a proxy for the innovation to common technology shock, $\varepsilon_{t}$ ) is found to be 0.011 , similar to the value used in Romer (2006). The deterministic trend in technology growth, $\mu$, is obtained by calculating the mean of the growth rate of per capita real GDP in logarithm in the United States between 1985Q1 and 2009Q4. $\mu$ is found to be around 0.003, which implies a per capita output growth rate of around $1.2 \%$, per annum. The autoregressive coefficient of the growth rate of per capita real GDP (in logarithm) is 0.439 , which is taken as the coefficient of autoregression in the common technology shock, $\rho_{u}$. To match an annualized default probability of around 3.4 per cent (a quarterly rate of 0.86 per cent), consistent with BGG and the rolling 12-month quarterly default rate of U.S. private firms provided by Moody's from 2000 to 2009, we set the standard deviation of the idiosyncratic

\footnotetext{
${ }^{13}$ A detailed description of the U.S. data series used for calibration can be found in Appendix B.

${ }^{14}$ For details on the HP filter, see, for example, King and Rebelo (1993) and Hodrick and Prescott (1997). The cyclical component $y_{t}^{c}$ of the series extracted by an HP filter is defined by (in the infinite sample version of the HP filter) $y_{t}^{c}=\frac{\lambda(1-L)^{2}\left(1-L^{-1}\right)^{2}}{1+\lambda(1-L)^{2}\left(1-L^{-1}\right)^{2}} y_{t}$, where $y_{t}$ is the original time series, $L$ is the lag operator and $\lambda$ is the smoothing parameter. Alternative approaches for permanent-transitory decomposition include the Beveridge-Nelson procedure (see, for example, Garratt, Lee, Pesaran, and Shin, 2006).
} 
technology shock, $\sigma_{\lambda}$, to $0.43 .^{15}$

We calibrate the values for the standard deviation and the autoregressive coefficient of the credit shock using U.S. data on loans and deposits between 1985Q1 to 2009Q4. First, we define a series that is the difference between the logarithm of per capita loans and the logarithm of per capita deposits. We then detrend the series using an HP filter (with the smoothing parameter of 1600) and take the cyclical components of the series as a proxy for $\eta_{t}$. The standard deviation of the series, $\sigma_{\eta}$, is found to be 0.011 , and the autoregressive coefficient of the credit shock process, $\rho_{\theta}$, is estimated to be 0.848 .

The leverage factor of firms is derived using the Federal Reserve Flow of Funds data, Table L.102 (levels data) on U.S. non-farm non-financial corporate business, following Fiore and Uhlig (2005). Debt is defined as bank loans and corporate bonds (lines 39+26), and equity is defined as the market value of equities outstanding (line 37). The proportion of debt finance in total finance between 1985Q1 to 2009Q4 is around 30 per cent, which implies a firm leverage ratio of around 1.43. ${ }^{16}$ Finally, we consider three different values of $\mu_{\theta}$, the mean of the loan-to-deposit ratio in our calibration exercises, $\mu_{\theta}=\{0.95,1,1.05\}$.

Table 2: Steady-State Values and the Loan-to-Deposit Ratio

\begin{tabular}{|c|c|c|c|c|c|c|c|c|c|c|c|}
\hline & \multicolumn{10}{|c|}{ Steady-state values } \\
\hline & & $r_{d}^{*}$ & $r_{l}^{*}$ & $\stackrel{\circ}{N}^{*}$ & $\stackrel{\circ}{W}^{*}$ & $\stackrel{\circ}{ }^{*}$ & $\dot{Y}^{*}$ & $\stackrel{\circ}{K}^{*}$ & $\stackrel{\circ}{L}^{*}$ & $\dot{S}^{*}$ & $\stackrel{\circ}{D}^{*}$ \\
\hline \multirow{3}{*}{$\mu_{\theta}$} & 0.95 & 0.007 & 0.121 & 1 & 0.350 & 0.369 & 0.538 & 0.167 & 0.050 & 0.117 & 0.053 \\
\hline & 1 & 0.007 & 0.070 & 1 & 0.360 & 0.373 & 0.553 & 0.181 & 0.054 & 0.126 & 0.054 \\
\hline & 1.05 & 0.007 & 0.021 & 1 & 0.369 & 0.376 & 0.568 & 0.195 & 0.058 & 0.136 & 0.056 \\
\hline
\end{tabular}

Note: The steady-state values are computed based on the parameter values given in Table 1 . The steady state of labour hours in efficiency unit $N^{*}$ is normalized to 1 .

The steady-state values of the model variables in efficiency units provided in Table 2 are obtained using equations (3.22) to (3.27). It is interesting to note that, in the steady state, output per capita, consumption per capita and capital per capita in efficiency units rise with $\mu_{\theta}$, which measures the availability of loans and the extent of leverage in the banking sector. This finding suggests that, as the banking sector becomes more leveraged and the extent of financial intermediation increases, the steady-state level of output per capita in the economy tends to be higher. This result is consistent with empirical studies of the relationship between finance and development, where a more developed banking sector is often associated with faster economic development (see, for example, Levine, 2005). Note also that, when the banking sector becomes more leveraged, the interest rate charged on loans tends to fall. For example, when $\mu_{\theta}$ increases from 1 (no leverage) to 1.05 , the real loan rate falls from an implausibly high rate of 7 per cent per quarter $(28$ per cent per annum) to around 8 per cent per annum, yielding an interest rate spread of around 5 per cent per annum, which is more reasonable. The results suggest that, in order to meet the break-even condition, in equilibrium the banking sector could either charge a high interest rate on loans to

\footnotetext{
${ }^{15}$ See, for example, Moody's (2012). The data source is Moody's Analytics Credit Research Database (CRD), which collects quarterly data from 15 U.S. lending organizations, representing both large institutions and smaller regional banks. The CRD definition of default is consistent with the Basel II directive.

${ }^{16}$ This result is very similar to Fiore and Uhlig (2005), who find that the debt to total finance ratio is around 0.3 and a leverage ratio of around 1.43 for US non-farm, non-financial corporate business sector, using the shorter sample period of 1997 to 2003.
} 
cover the losses resulting from firm defaults, or take on more risks by increasing leverage, in the form of security issuance, for example.

Table 3: Steady-State Values and Default Probability

\begin{tabular}{|c|c|c|c|c|c|c|c|c|c|c|c|c|}
\hline & \multicolumn{10}{|c|}{ "Steady-state values } & \multirow[t]{2}{*}{ Default Prob } \\
\hline & & $r_{d}^{*}$ & $r_{l}^{*}$ & $\stackrel{\circ}{N}^{*}$ & $\stackrel{\circ}{W}^{*}$ & $\stackrel{\circ}{C}^{*}$ & $\stackrel{\circ}{Y}^{*}$ & $\stackrel{\circ}{K}^{*}$ & $\stackrel{\circ}{L}^{*}$ & $\stackrel{\circ}{S}^{*}$ & $\stackrel{\circ}{D}^{*}$ & \\
\hline \multicolumn{13}{|c|}{ Panel A } \\
\hline & 1.25 & 0.007 & 0.033 & 1 & 0.367 & 0.373 & 0.564 & 0.191 & 0.038 & 0.153 & 0.038 & 0.0026 \\
\hline \multirow[t]{2}{*}{$v$} & 1.43 & 0.007 & 0.070 & 1 & 0.360 & 0.373 & 0.553 & 0.181 & 0.054 & 0.126 & 0.054 & 0.0086 \\
\hline & 1.67 & 0.007 & 0.148 & 1 & 0.345 & 0.370 & 0.531 & 0.160 & 0.064 & 0.096 & 0.064 & 0.0233 \\
\hline \multicolumn{13}{|c|}{ Panel B } \\
\hline \multirow{3}{*}{$\sigma_{\epsilon}$} & 0.001 & 0.007 & 0.070 & 1 & 0.360 & 0.373 & 0.554 & 0.181 & 0.054 & 0.126 & 0.054 & 0.0086 \\
\hline & 0.011 & 0.007 & 0.070 & 1 & 0.360 & 0.373 & 0.553 & 0.181 & 0.054 & 0.126 & 0.054 & 0.0086 \\
\hline & 0.110 & 0.007 & 0.085 & 1 & 0.357 & 0.372 & 0.550 & 0.177 & 0.053 & 0.124 & 0.053 & 0.0105 \\
\hline \multicolumn{13}{|c|}{ Panel C } \\
\hline \multirow{3}{*}{$\sigma_{\lambda}$} & 0.33 & 0.007 & 0.013 & 1 & 0.369 & 0.372 & 0.568 & 0.196 & 0.059 & 0.137 & 0.059 & 0.0009 \\
\hline & 0.43 & 0.007 & 0.070 & 1 & 0.360 & 0.373 & 0.553 & 0.181 & 0.054 & 0.126 & 0.054 & 0.0086 \\
\hline & 0.53 & 0.007 & 0.221 & 1 & 0.333 & 0.369 & 0.513 & 0.144 & 0.043 & 0.101 & 0.043 & 0.0281 \\
\hline
\end{tabular}

Note: The steady-state values in Panels A, B and $\mathrm{C}$ are computed based on the parameter values given in Table 1 , with $\mu_{\theta}=1$ and the values of $v, \sigma_{\epsilon}$ and $\sigma_{\lambda}$ given in this table, respectively. The steady state of labour hours in efficiency unit $\stackrel{\circ}{N}^{*}$ is normalized to 1 .

Since an important focus of this paper is to examine the impact of firm defaults on macroeconomic conditions, we also compute the steady-state values of the model economy by varying some of the key parameters that determine the equilibrium default probability, namely, the leverage ratio of the firms, $v$, and the standard deviations of common and idiosyncratic technology shocks, $\sigma_{\epsilon}$ and $\sigma_{\lambda}$. Recall from (2.26) and (2.27) that default probability rises with a firms' leverage ratio and the standard deviations of technology shocks. The results in Table 3 confirm this prediction in the steady states. For the firms' leverage ratio, $v$, we consider three scenarios with $v=\{1.25,1.43,1.67\}$, where the proportion of debt finance to total finance is 20 per cent, 30 per cent (U.S. data), and 40 per cent, respectively. As the results in Table 3 show, the probability of default rises from 0.086 per cent to 2.33 per cent per quarter when the leverage ratio increases from 1.43 to 1.67 , and the interest rate on loans doubles from 7 per cent to 14.8 per cent. We also observe a fall in the steady-state levels of per capita consumption, output and capital, when the firm's leverage ratio rises, despite an increase in the level of loans per capita, since a larger proportion of the loans are non-performing and the steady-state value of private equity per capita is falling (the substitution effect). As expected, the probability of default rises with the volatility of common and idiosyncratic technology shocks (see Panels B and C of Table 3). The steady-state levels of per capita output, consumption and loans decline with increased volatility. Finally, note that in the steady state, $\stackrel{\circ}{Y}^{*}=\stackrel{\circ}{C}^{*}+\stackrel{\circ}{S}^{*}+\stackrel{\circ}{D}^{*}$; that is, output is divided into consumption and savings, comprising private-equity investment, $S^{*}$, and bank deposits, $D^{*}$, as implied by equation $(3.15)$. 


\section{Results of the Calibration Exercise}

\subsection{Effects of credit shocks}

We consider the impacts of a positive credit shock. ${ }^{17}$ As can be seen in Figure 1, the impulse responses for a positive credit shock yield an increase in loans of around 1 per cent on impact. ${ }^{18}$

Figure 1: Impulse responses of one-standard-deviation positive credit shock (Benchmark Calibration, $\mu_{\theta}=1$, per cent per quarter)
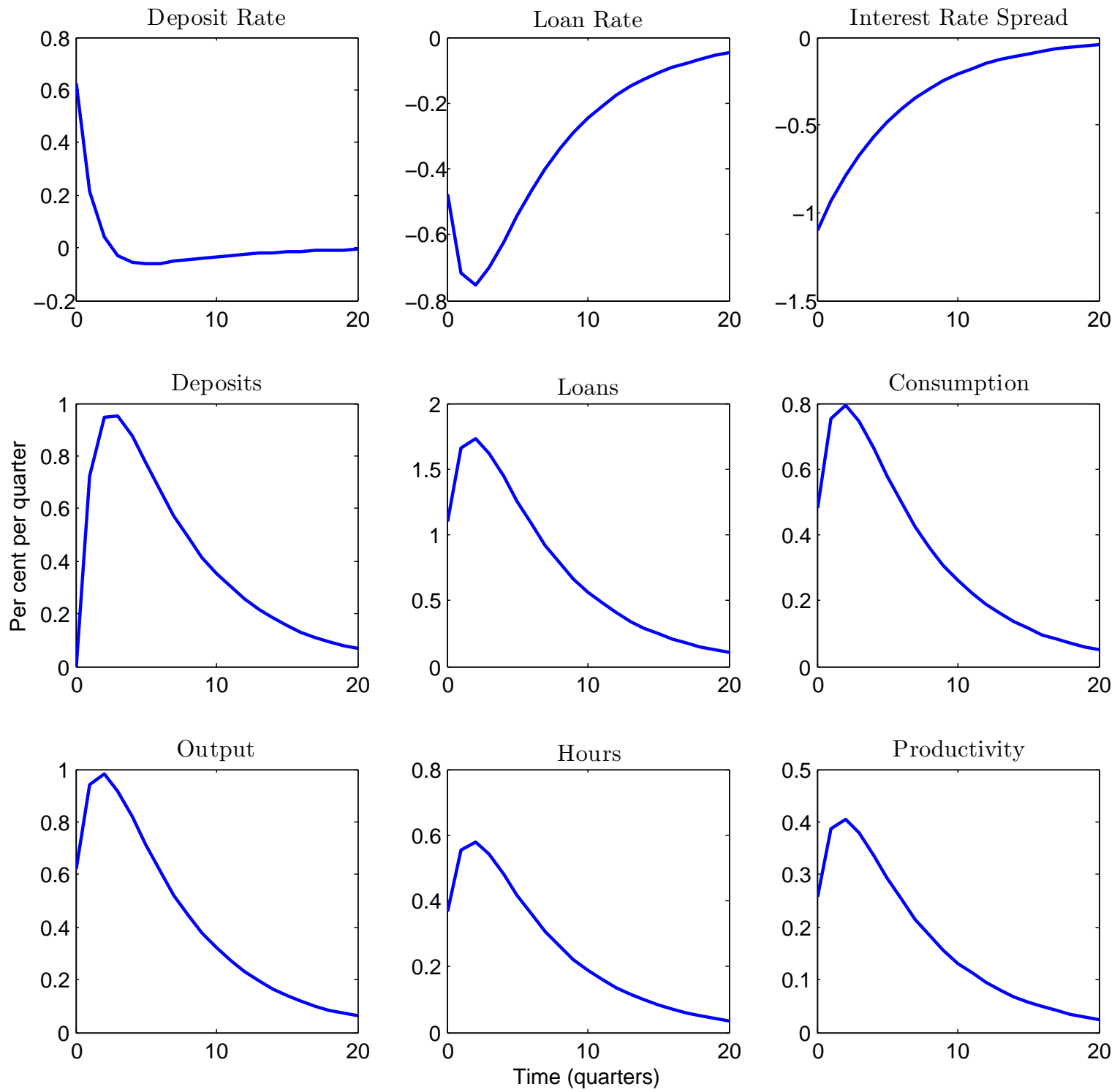

The rise in the level of loans leads to an increase in available capital in the economy and a rise in output level of around 0.6 per cent. The increase in the supply of funds also drives down the interest rate on loans by almost half a per cent and leads to a fall in the interest rate spread by around 1 per cent, as predicted by Proposition 2. The deposit rate rises by about 0.6 per cent on impact, which in turn implies an increase in the level of deposits of around 1 per cent at its peak, consistent with the zero-profit condition imposed on the banking sector. In the absence of a

\footnotetext{
${ }^{17}$ The parameter values are given in Table 1 , with the mean of the loan-to-deposit ratio, $\mu_{\theta}$, set at one.

${ }^{18} \mathrm{~A}$ negative credit shock can be interpreted as a credit crunch.
} 
technology shock, labour hours rise in response to the decline in loan interest rates (see Proposition 2). The resulting increase in labour income raises household consumption by around 0.4 per cent on impact. Further, productivity rises, since output increases more than labour hours on impact. Our findings are consistent with the impulse responses of a shock to bank capital, which predict that the level of loans, output, labour hours and household consumption move in the same direction (see, for example, Aikman and Paustian, 2006). It is worth highlighting that our findings are also in line with the empirical evidence of responses to a U.S. credit shock, where output and shortterm interest rates (the deposit rate can be seen as a proxy) move in the same direction as the credit shock (see, for example, Helbling, Huidrom, Kose, and Otrok, 2011 and Xu, 2012). Our calibrated results show that the speed of convergence to equilibrium is slow for the credit shock (around 20 quarters), while the peak impacts of a credit shock on output and consumption are much larger than the effects of a typical technology shock. This observation is consistent with empirical studies on the output effect of financial crises, which suggest that recessions associated with financial crises have been much longer lasting than recessions associated with other shocks (see, for example, IMF, World Economic Outlook, April 2009, Chapter 3). The prolonged effects of the credit shock also reflect the high persistence in the loan-to-deposit ratio that we observe empirically, where the autoregressive coefficient of the credit shock is found to be 0.848 , while the autoregressive coefficient of the technology shock is typically set to around 0.44 in calibration exercises.

\subsection{Robustness of the results}

\subsubsection{Alternative mean of the loan-to-deposit ratio}

In order to check the robustness of our calibrated results, we carry out three additional experiments.

First, we examine the sensitivity of the impulse responses of a positive credit shock to the mean of the loan-to-deposit ratio, $\mu_{\theta}$. As seen in Table 2, the steady-state values of output per capita, consumption per capita and interest rate spreads are sensitive to the choice of $\mu_{\theta}$. The impulse responses in Figure 2 suggest that, while the steady-state values are sensitive to the value of $\mu_{\theta}$, the impulse responses to a positive credit shock and the dynamics of the model are robust to the mean of the loan-to-deposit ratio in the economy. We also find similar results for the technology shock. ${ }^{19}$

\subsubsection{Lower persistence in the credit shock}

In the second experiment, we consider the robustness of our results to the value of $\rho_{\theta}$, the autoregressive coefficient of the credit shock. We reduce the benchmark estimate of $\rho_{\theta}$ from 0.848 to 0.678 (by 20 per cent). The results are displayed in Figure 3. We observe faster convergence in the impact of the credit shock when the autoregressive coefficient is reduced; in particular, the impact on output takes approximately 8 to 10 quarters to vanish, compared with around 20 quarters in the benchmark case. The magnitude of the response in the levels of loans, output and consumption is robust on impact, around twice as large as the impact of a technology shock, which is consistent

\footnotetext{
${ }^{19}$ Owing to space considerations, the impulse responses to a positive technology shock are not presented here, but are available upon request.
} 
Figure 2: Impulse responses of one-standard-deviation positive credit shock $\left(\mu_{\theta}=1.05,1\right.$ and 0.95$)$
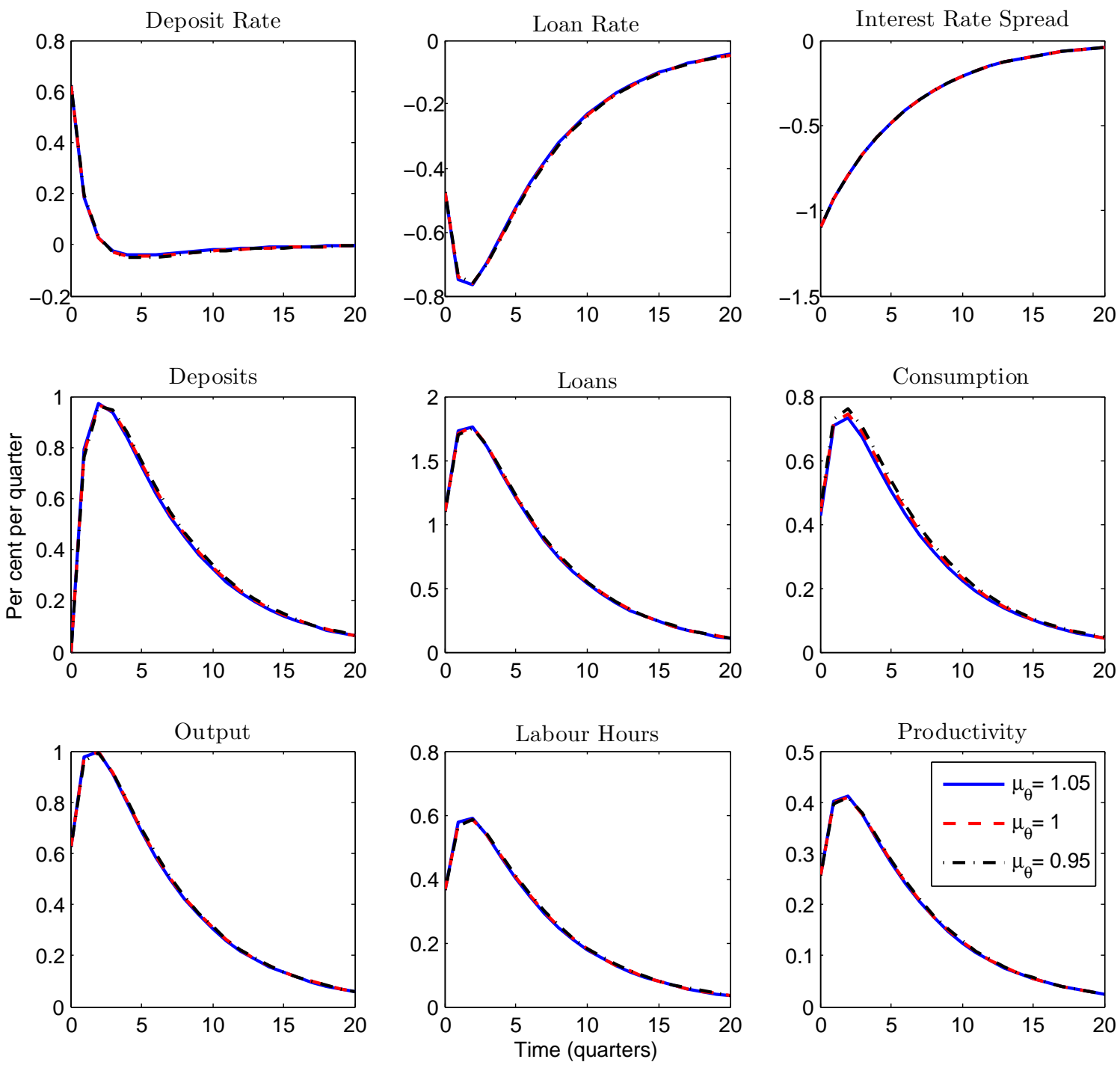

with the empirical evidence that recessions associated with financial crisis tend to be more severe than recessions associated with other shocks. We also find a lower value for the peak impact of a positive credit shock on output when $\rho_{\theta}$ is reduced.

\subsubsection{Higher volatility in the credit shock}

In the third experiment, we increase the volatility of the credit shock, as measured by $\sigma_{\eta}$, by 50 per cent above the value implied by U.S. data, thus increasing $\sigma_{\eta}$ from 1.1 per cent to 1.65 per cent. As shown in Figure 4, the peak response in output, consumption and the level of loans is around 50 per cent higher when $\sigma_{\eta}=1.65 \%$. We also note a slower rate of convergence to equilibrium. The volatility of the credit shock, $\sigma_{\eta}$, has an impact on the dynamics of the model, since it affects the steady-state conditions of the model through $E\left(\ln \theta_{t}\right)$, given by equation (2.42), and therefore enters the coefficients of the log-linearized approximation of the equilibrium conditions. This result confirms our finding that a credit shock could have a profound impact on the real economy, in terms of both the magnitude and duration of the responses, and the impact could be even more severe 
Figure 3: Impulse responses of one-standard-deviation positive credit shock $\left(\rho_{\theta}=0.848\right.$ and $\left.0.678, \mu_{\theta}=1\right)$
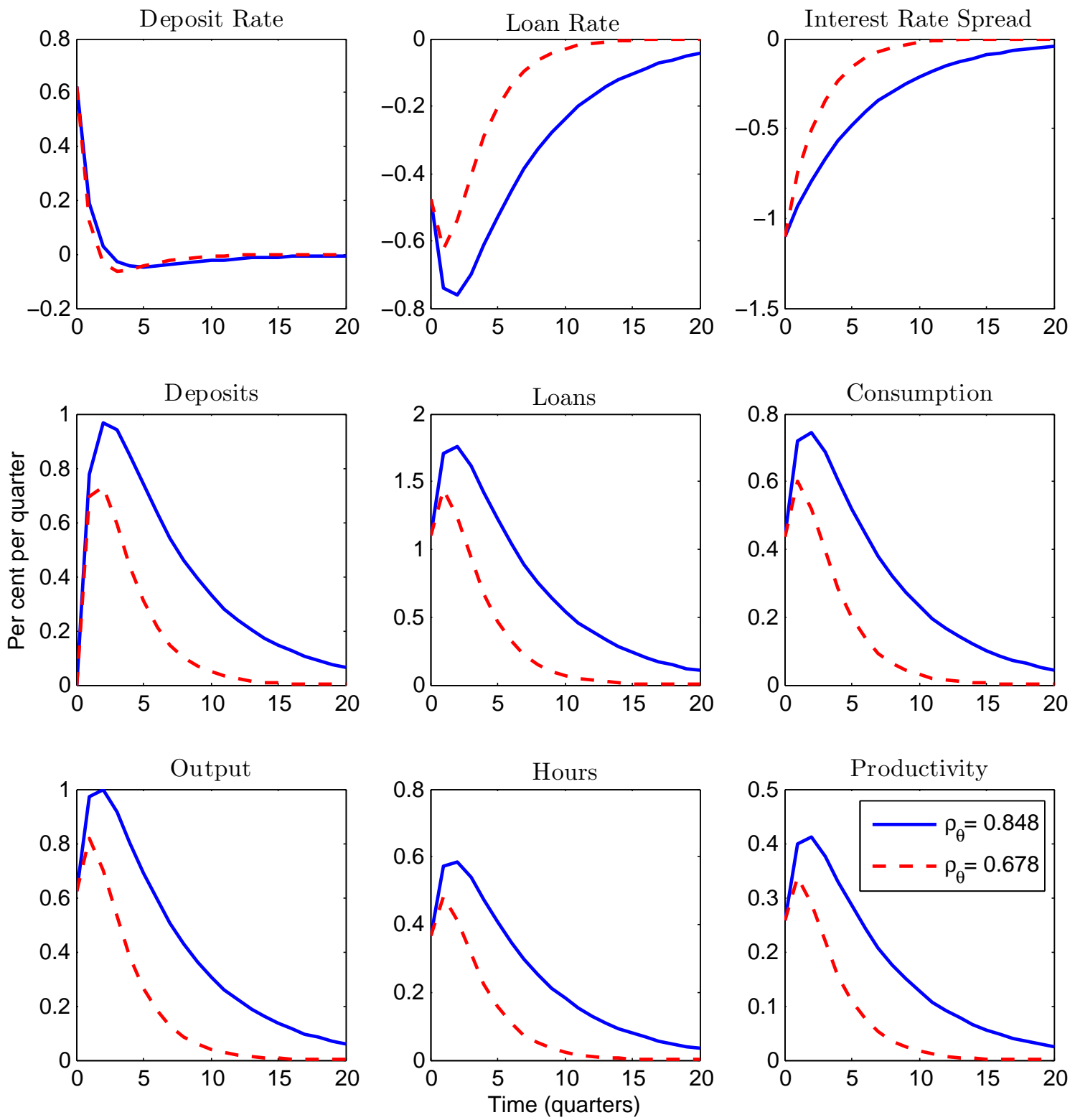

during a banking crisis that is combined with elevated market volatility.

\section{A Selected Review of the Literature}

In this section, we provide a brief account of the macroeconomic literature related to the modelling of financial intermediation. We start with an overview of models of financial intermediation that focus on the demand and supply of credit and highlight the relationship between financial frictions and monetary policy. We then review alternative approaches in the literature to modelling credit risk and firm defaults.

Over the past decade, there have been significant advances in the theoretical literature on the macroeconomic implications of financial imperfections. These advances are partly motivated by the limitations of the traditional monetary policy channel in explaining the time-series empirical 
Figure 4: Impulse responses of one-standard-deviation positive credit shock $\left(\sigma_{\eta}=1.1 \%\right.$ and $\left.1.65 \%, \mu_{\theta}=1\right)$
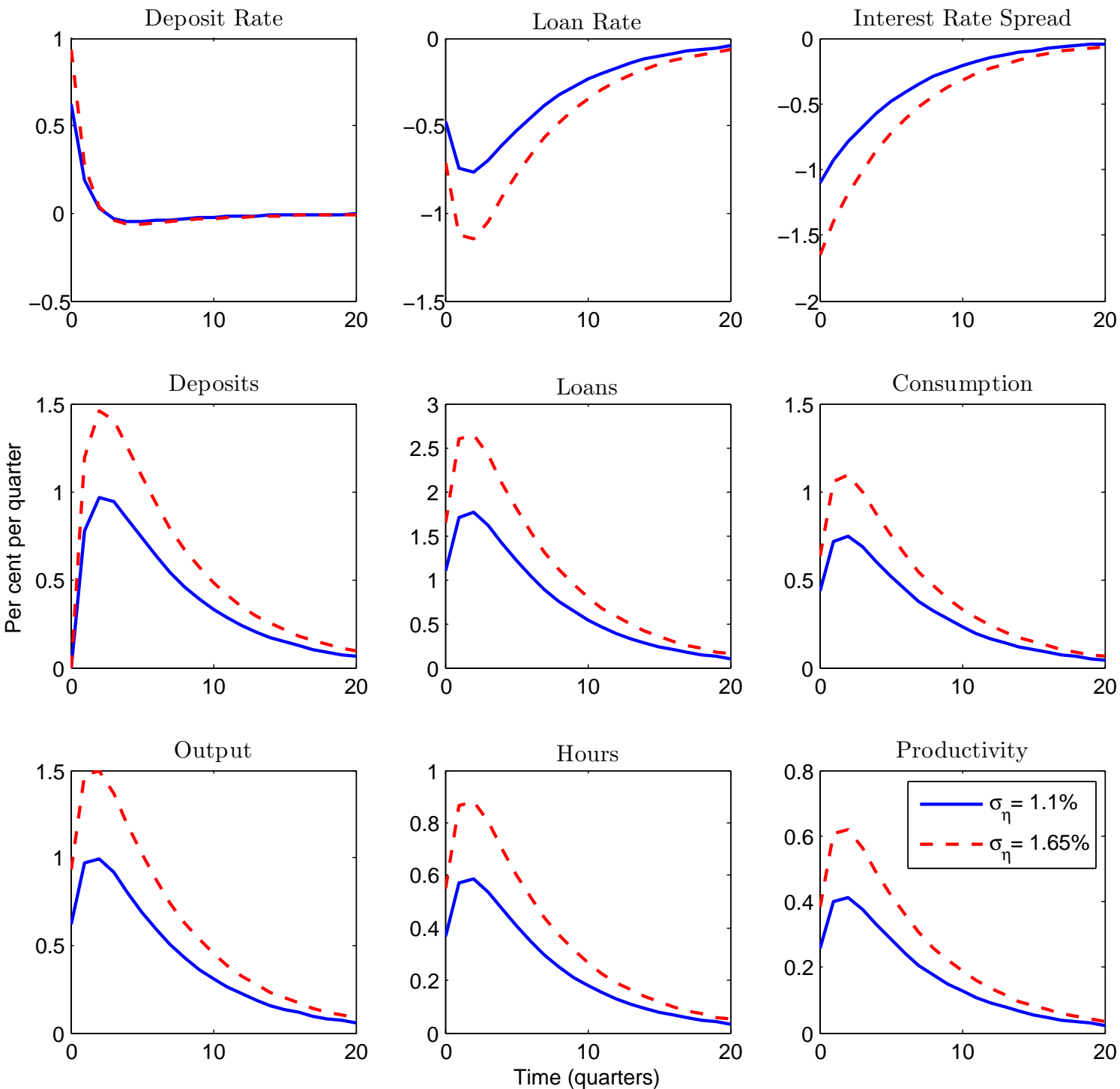

evidence of the effects of monetary policy on the economy. ${ }^{20}$ This has led to a search for alternative theories. One line of the research focuses on the credit channels of monetary policy and examines the extent to which imperfect information and other financial frictions in the credit market affect the transmission of monetary policy. ${ }^{21}$ Financial market imperfections could be due to a number of factors: first, the asymmetry of information between lenders and borrowers (see, for example, Bernanke and Gertler, 1995, Bernanke, Gertler, and Gilchrist, 1999 and Gilchrist, 2004), which induces the lenders to engage in costly monitoring activities. ${ }^{22}$ The extra cost of monitoring by

\footnotetext{
${ }^{20}$ For example, Bernanke and Gertler (1995) argue that it is difficult to explain the magnitude, timing and composition of the economy's response to monetary policy shocks solely in terms of conventional interest rate (neoclassical cost of capital) effects. Empirically, the interest rate spike associated with an unanticipated monetary tightening is largely transitory, yet some important components of spending do not begin to react until after most of the interest rate effects have past.

${ }^{21}$ According to Bernanke and Gertler (1995), the credit channel is not considered to be a distinct, free-standing alternative to the traditional monetary policy transmission mechanism, but rather a set of factors that amplify and propagate conventional interest rate effects.

${ }^{22}$ For example, costly state verification, in which lenders must pay a fixed "auditing cost" to observe an individual borrower's realized return, first introduced in Townsend (1979) and further developed in Bernanke, Gertler, and
} 
lenders gives rise to an external finance premium for the firms, which represents a wedge between a firm's own opportunity cost of funds and the cost of external finance. Higher asset prices improve the firm's balance sheets, reduce the external finance premium, increase borrowing and stimulate investment spending. The rise in investment further increases asset prices and net worth, giving rise to an amplified impact on investment and output in the economy. Financial frictions act as a financial accelerator that leads to an amplification of business-cycle fluctuations, working their effects through the "credit channel" of monetary policy.

Financial frictions could also stem from the lending collateral constraints faced by borrowers. Examples of this line of research can be found in Kiyotaki and Moore (1997), Carlstrom, Fuerst, and Paustian (2010), and Gertler and Kiyotaki (2010). Credit constraints arise because lenders cannot force borrowers to repay their debts unless the debts are secured by some form of collateral. Borrowers' credit limits are affected by the prices of the collateralized assets. These asset prices are in turn influenced by the size of the credit limits, which affects investment and demand for assets in the economy. The dynamic interaction between borrowing limits and the prices of assets amplifies the impact of a small initial shock and generates large and persistent fluctuations in output and asset prices in the economy.

In addition to frictions in the demand for credit from firms, a number of recent papers argue that banks themselves are also subject to frictions when raising loanable funds. These frictions indicate that the supply side of the credit market also contributes to shock propagation, affecting output dynamics in the economy. In Meh and Moran (2010), moral hazard arises, since the monitoring activities of banks are not publicly observable. Depositors are concerned that banks may not monitor entrepreneurs adequately and demand that banks invest their own net worth (bank capital) in the financing of entrepreneurial projects. The capital position of banks therefore affects their ability to attract loanable funds. The additional financial frictions between banks and their depositors constrain the supply of credit and therefore the leverage of entrepreneurs in the economy. The "bank capital channel" propagates a negative technology shock through a reduction in the profitability of bank lending, making it more difficult for banks to attract loanable funds. Banks are forced to finance a larger proportion of capital investments using their own capital, and reduce bank lending, since bank capital consists mostly of retained earnings and cannot adjust immediately. Reduced bank lending in turn leads to a fall in investment and economic activity. ${ }^{23}$

Several papers argue that the degree of competition in the banking sector, or the rate-setting strategies of banks, contribute to frictions on the supply side of credit markets, which are also important in explaining macroeconomic fluctuations. Gerali, Neri, Sessa, and Signoretti (2010) model an imperfectly competitive banking sector that enjoys some degree of market power in loan and deposit markets and sets different rates for households and firms. Based on Bayesian estimation using euro-area data, they find that the banking sector attenuates the effects of monetary policy shocks, since sticky rates moderate the impact of changes in the policy rate on both consumption and investment. On the other hand, financial intermediation increases the propagation of supply shocks originating in credit markets, which are linked to asset prices and the balancesheet conditions of borrowers. In a related paper, Hulsewig, Mayer, and Wollmershaeuser (2006) study the role of banks in the "cost channels" of monetary policy. They assume that banks extend Gilchrist (1999).

${ }^{23}$ Papers that use a similar approach include Chen (2001) and Aikman and Paustian (2006). 
loans to firms in an environment of monopolistic competition by setting the loan rate according to a Calvo-type staggered price-setting mechanism. ${ }^{24}$ These authors find that frictions in the loan market influence the propagation of monetary policy shocks, since the pass-through of a change in the money market rate to the loan rate is incomplete. However, the strength of the cost channel is mitigated, since banks shelter firms from monetary policy shocks by smoothing the lending rates. ${ }^{25}$

In addition to the above channels of monetary policy, Adrian and Shin (2009) propose that the balance sheets of financial intermediaries also contribute to a "risk-taking channel", involving the bank's net interest margin, defined as the difference between the total interest income on the asset side and the interest expense on the liabilities side of the bank's balance sheet. A rise in the net interest margin (owing to changes in the policy rate) raises the profitability of bank lending and increases the present value of bank income, therefore boosting the forward-looking measures of bank capital. As banks expand their balance sheets, the market price of risk falls and the supply of credit increases. As a result, financial intermediaries drive the financial cycle and affect the real economy through their influence on the determination of the price of risk.

A number of recent papers also develop quantitative models to explore the effects of unconventional monetary policy instruments, such as direct lending by central banks, to capture the policy responses following the financial crisis of 2007-2009. See, for example, Christiano, Ilut, Motto, and Rostagno (2010), Gertler and Kiyotaki (2010) and Gertler and Karadi (2011, 2013). Gertler and Karadi (2011) interpret unconventional monetary policy as expanding central bank credit intermediation to offset a disruption to private financial intermediation. They model unconventional monetary policy by allowing the central bank to act as intermediary by borrowing funds from savers and then lending them to investors. The central bank is distinct from private intermediaries (commercial banks) in two ways. First, the central bank does not face constraints on its leverage ratio. Second, public intermediation is likely to be less efficient than the private intermediation. Their findings suggest that during a financial crisis like the recent one, the balance-sheet constraints on private intermediaries tighten, raising the benefits of and the needs for central bank intermediation. In a related paper, Gertler and Kiyotaki (2010) consider two additional unconventional monetary policy instruments, discount-window lending to banks secured by private credit and direct assistance to large financial institutions, including equity injections, and examine their impact during a crisis period. ${ }^{26}$

As this short review suggests, the existing literature on financial frictions and credit markets is largely monetary in nature and is motivated to examine the impact of monetary policy on macroeconomic fluctuations. However, as noted already, our focus is on examining the relationship between credit, firm defaults and volatility, and studying the impact of a credit shock on the macro-economy. Related to the modelling of firm defaults, one way to classify credit risks is to distinguish between microeconomic or idiosyncratic risks, which can be diversified through the law

\footnotetext{
${ }^{24}$ The "cost channels" of monetary policy capture the impact of interest rates and credit conditions on the short-run ability of firms to produce (by investing in working capital). See, for example, Barth and Ramey (2000), Christiano, Eichenbaum, and Evans (2005), Chowdhury, Hoffmann, and Schabert (2006), and Ravenna and Walsh (2006).

${ }^{25}$ One explanation for the imperfection in the loan market is the existence of long-term relationships between banks and customers, which are typical for a bank-based financial system as opposed to a market-based financial system. See, for example, Fried and Howitt (1980) and Berger and Udell (1992).

${ }^{26}$ Several papers also explore the advantage of incorporating credit variables in the Taylor rule. Christiano, Ilut, Motto, and Rostagno (2008) find that a Taylor rule modified to include a response to variations in some measure of aggregate credit would be an improvement upon conventional policy advice. Curdia and Woodford (2010) find that an adjustment for variations in credit spreads can improve upon the standard Taylor rule.
} 
of large numbers, and macroeconomic or systematic risks, which cannot. Banks generally have to deal with both types of risks. Freixas and Rochet (2008) argue that defining and measuring credit risk is equivalent to determining how the market evaluates the probability of default by a particular borrower, taking into account all the possibilities of diversification and hedging provided by financial markets.

Our analysis is closely related to the modelling approaches of BGG and Christiano, Ilut, Motto, and Rostagno (2010). ${ }^{27}$ In BGG, entrepreneurial loans are risky and returns on the underlying investments are subject to idiosyncratic and common shocks. A sufficiently unfavorable shock can lead to the borrower's bankruptcy. The idiosyncratic shock is observed by the entrepreneur, but not by the bank, which, as in Townsend (1979), must pay a fixed monitoring cost to observe the entrepreneurs' realized return. To mitigate problems stemming from this source of asymmetric information, entrepreneurs and the bank sign a standard debt contract. Under this contract, the entrepreneur commits to paying back the loan principal plus an interest charge, unless it declares default. In case of default, the bank conducts a costly state verification of the residual value of the entrepreneur's assets and seizes the assets as partial compensation. Our paper differs from BGG in that the idiosyncratic shocks affect productivity rather than the return on capital in the economy, which keeps the model tractable and allows us to establish a direct link between technology shocks and probability of default. ${ }^{28}$ We also allow households to bear part of the default risk through their equity investments in the firms, in the face of an adverse technology shock; otherwise, the whole burden of default falls on the banking sector, resulting in unexpectedly high spreads between loan and deposit rates.

\section{Conclusion}

This paper develops an analytically tractable theoretical model to analyze the relationship between credit, firm default and volatility, with the aim of studying the effects of credit shocks on the real economy. It advances a new approach to modelling firm defaults and financial intermediation, and examines the financial implications of such defaults on the behavior of the household and the banking sector. It also incorporates growth into a DSGE framework and proposes a new method of computing steady states, allowing the steady-state values of the model to depend on the volatility of the technology shocks and credit shocks.

We show that, in the steady state, the probability of firm default rises with firm's leverage ratio and the level of uncertainty in the macroeconomy. A positive credit shock, defined as a rise in the loan-to-deposit ratio, leads to an increase in available capital and a rise in output, which is largely consistent with the empirical findings in the companion paper $\mathrm{Xu}$ (2012). The positive credit shock also drives down the spread between the loan rate and the deposit rate. The effects of the credit shock are found to be very persistent and profound, consistent with empirical studies on the output effects of financial crises, which suggest that recessions associated with financial crisis have lasted much longer than recessions associated with other shocks.

The current modelling framework can be extended and enhanced along several dimensions.

\footnotetext{
${ }^{27}$ Several other papers models firm defaults in a similar fashion. See, for example, Fiore and Tristani (2009).

${ }^{28}$ Christiano, Ilut, Motto, and Rostagno (2010) assume that the variance of the idiosyncratic shock that hits the entrepreneur's return is the realization of a time-varying process.
} 
First, a more elaborate banking sector including bank capital can be considered, to allow for endogenous credit shocks and leverage shocks. Second, it would be important to consider the risks of high leverage as well as the benefits, which were highlighted in the current framework. One way to introduce the potential costs of leverage is to augment the model with price rigidities and a central bank operating under a monetary policy rule such as the Taylor rule. This would allow one to capture possible inflationary pressure from high leverage and to study the policy implications of credit shocks. Alternatively, one could incorporate leverage costs in the production function, to establish a direct link between excess leverage and low productivity in the economy. Third, it would be interesting to extend the model to incorporate time-varying volatility, and to study the evolution of the probability of firm default over the business cycle. 


\section{References}

Adrian, T., AND H. S. Shin (2009): "Financial Intermediaries and Monetary Economics," Federal Reserve Bank of New York Staff Reports 398.

Aikman, D., And M. Paustian (2006): "Bank capital, asset prices and monetary policy," Bank of England working papers 305, Bank of England.

Arellano, C. (2008): "Default Risk and Income Fluctuations in Emerging Economies," American Economic Review, $98(3), 690-712$.

Bagliano, F. C., AND C. Morana (2012): "The Great Recession: US dynamics and spillovers to the world economy," Journal of Banking \& Finance, 36(1), 1-13.

Barth, M. J., And V. A. RAmey (2000): "The Cost Channel of Monetary Transmission," NBER Working Papers 7675, National Bureau of Economic Research, Inc.

Berger, A. N., AND G. F. Udell (1992): "Some Evidence on the Empirical Significance of Credit Rationing," Journal of Political Economy, 100(5), 1047-1077.

Bernanke, B., And M. Gertler (1995): "Inside the Black Box: The Credit Channel of Monetary Policy Transmission," Journal of Economic Perspectives, 9(4), 27-48.

Bernanke, B., M. Gertler, And S. Gilchrist (1999): "The Financial Accelerator in a Quantitative Business Cycle Framework," in Handbook of Macroeconomics, ed. by J. B. Taylor, and M. Woodford, vol. 1, chap. 21, pp. 1341-1393.

Binder, M., AND M. H. Pesaran (1995): "Multivariate Rational Expectations Models and Macroeconomic Modelling: A Review and Some New Results," in Handbook of Applied Econometrics, ed. by M. H. Pesaran, and M. Wickens, pp. 139-187. Blackwells, Oxford.

(1997): "Multivariate Linear Rational Expectations Models: Characterization of the Nature of the Solutions and Their Fully Recursive Computation," Econometric Theory, 13(6), 877-888.

(1998): "Decision Making in the Presence of Heterogeneous Information and Social Interactions," International Economic Review, 39(4), 1027-1052.

(2001): "Life-cycle Consumption under Social Interactions," Journal of Economic Dynamics and Control, 25(1-2), 35-83.

Bloom, N. (2009): "The Impact of Uncertainty Shocks," Econometrica, 77(3), 623-685.

Carlstrom, C. T., T. S. Fuerst, And M. Paustian (2010): "Optimal Monetary Policy in a Model with Agency Costs," Journal of Money, Credit and Banking, 42(s1), 37-70.

Chatterjee, S., D. Corbae, M. Nakajima, And J.-V. Ros-Rull (2007): "A Quantitative Theory of Unsecured Consumer Credit with Risk of Default," Econometrica, 75(6), 1525-1589.

Chen, N.-K. (2001): "Bank Net Worth, Asset Prices and Economic Activity," Journal of Monetary Economics, 48(2), 415-436.

Chowdhury, I., M. Hoffmann, And A. Schabert (2006): "Inflation Dynamics and the Cost Channel of Monetary Transmission," European Economic Review, 50(4), 995-1016.

Christiano, L., M. Eichenbaum, And C. Evans (1997): "Sticky Price and Limited Participation Models of Money: A Comparison," European Economic Review, 41(6), 1201-1249.

- (2005): "Nominal Rigidities and the Dynamic Effects of a Shock to Monetary Policy," Journal of Political Economy, 113(1), 1-45.

Christiano, L., C. Ilut, R. Motto, And M. Rostagno (2008): "Monetary Policy and Stock Market Boom-Bust Cycles," Working Paper Series 955, European Central Bank.

(2010): "Financial Factors in Economic Fluctuations," Working Paper Series 1192, European Central Bank.

Curdia, V., AND M. Woodford (2010): "Credit Spreads and Monetary Policy," Journal of Money, Credit and Banking, 42(s1), 3-35.

Devereux, M. B., AND A. Sutherland (2011): "Country Portfolios In Open Economy Macro-Models," Journal of the European Economic Association, 9(2), 337-369.

Fiore, F. D., AND O. Tristani (2009): "Optimal monetary policy in a model of the credit channel," Working Paper Series 1043, European Central Bank.

Fiore, F. D., AND H. Uhlig (2005): "Bank Finance versus Bond Finance - What Explains the Differences between US and Europe?," Working Paper Series 547, European Central Bank.

Freixas, X., AND J.-C. Rochet (2008): Microeconomics of Banking, 2nd Edition. The MIT Press.

Fried, J., AND P. HowitT (1980): "Credit Rationing and Implicit Contract Theory," Journal of Money, Credit 
and Banking, 12(3), 471-487.

Garratt, A., K. Lee, M. H. Pesaran, And Y. Shin (2006): Global and National Macroeconometric Modelling. Oxford University Press.

Gerali, A., S. Neri, L. Sessa, And F. M. Signoretti (2010): "Credit and Banking in a DSGE Model of the Euro Area," Journal of Money, Credit and Banking, 42(s1), 107-141.

Gertler, M., AND P. Karadi (2011): "A Model of Unconventional Monetary Policy," Journal of Monetary Economics, 58(1), 17-34, Carnegie-Rochester Conference Series on Public Policy: The Future of Central Banking April 16-17, 2010.

(2013): "QE 1 vs. 2 vs. 3. . . : A Framework for Analyzing Large-Scale Asset Purchases as a Monetary Policy Tool," International Journal of Central Banking, 9(1), 5-53.

Gertler, M., AND N. Kiyotaki (2010): "Financial Intermediation and Credit Policy in Business Cycle Analysis," in Handbook of Monetary Economics, ed. by B. M. Friedman, and M. Woodford, vol. 3, chap. 11, pp. 547-599. Elsevier.

Gilchrist, S. (2004): "Financial Markets and Financial Leverage in a Two-Country World Economy," in Banking Market Structure and Monetary Policy, ed. by L. A. Ahumada, J. R. Fuentes, N. Loayza, and K. Schmidt-Hebbel, vol. 7 of Central Banking, Analysis, and Economic Policies Book Series, chap. 2, pp. 27-58. Central Bank of Chile.

Greenwood, J., Z. Hercowitz, And G. W. Huffman (1988): "Investment, Capacity Utilization, and the Real Business Cycle," American Economic Review, 78(3), 402-417.

Heer, B., And A. Maussner (2005): Dynamic General Equilibrium Modelling, Computational Methods and Applications. Springer.

Helbling, T., R. Huidrom, M. A. Kose, And C. Otrok (2011): "Do Credit Shocks Matter? A Global Perspective," European Economic Review, 55(3), 340-353.

Hodrick, R. J., And E. C. Prescott (1997): "Postwar U.S. Business Cycles: An Empirical Investigation," Journal of Money, Credit and Banking, 29(1), 1-16.

Hulsewig, O., E. Mayer, And T. Wollmershaeuser (2006): "Bank Behavior and the Cost Channel of Monetary Transmission," Cesifo working paper series, CESifo GmbH.

IMF (2009): "From Recession to Recovery: How Soon and How Strong?," World economic outlook, International Monetary Fund.

King, R. G., AND S. T. Rebelo (1993): "Low frequency filtering and real business cycles," Journal of Economic Dynamics and Control, 17(1-2), 207-231.

Kiyotaki, N., And J. Moore (1997): "Credit Cycles," The Journal of Political Economy, 105(2), 211-248.

Koop, G., M. H. Pesaran, And S. M. Potter (1996): "Impulse response analysis in nonlinear multivariate models," Journal of Econometrics, 74(1), 119-147.

Levine, R. (2005): "Finance and Growth: Theory and Evidence," in Handbook of Economic Growth, ed. by P. Aghion, and S. Durlauf, vol. 1 of Handbook of Economic Growth, chap. 12, pp. 865-934.

Magnus, J. R., AND H. Neudecker (1988): Matrix Differential Calculus with Applications in Statistics and Econometrics. Wiley Series in Probability and Statistics.

MeH, C., AND K. Moran (2010): "The role of bank capital in the propagation of shocks," Journal of Economic Dynamics and Control, 34(3), 555-576.

Meng, Q., AND A. Velasco (2003): "Indeterminacy in a small open economy with endogenous labor supply," Economic Theory, 22(3), 661-669.

Merton, R. C. (1974): "On the Pricing of Corporate Debt: The Risk Structure of Interest Rates," Journal of Finance, 29(2), 449-470.

Moody's (2012): "Moody's Analytics: Middle Market Risk Report," Moody's risk reports.

Pesaran, M. H., T. Schuermann, B.-J. Treutler, And S. M. Weiner (2006): "Macroeconomic Dynamics and Credit Risk: A Global Perspective," Journal of Money, Credit and Banking, 38(5), 1211-1261.

Pesaran, M. H., AND Y. Shin (1998): "Generalized impulse response analysis in linear multivariate models," Economics Letters, 58(1), 17-29.

Ravenna, F., AND C. WALsh (2006): "Optimal monetary policy with the cost channel," Journal of Monetary Economics, 53(2), 199-216.

Romer, D. (2006): Advanced Macroeconomics. McGraw-Hill/Irwin.

SAndleris, G. (2008): "Sovereign defaults: Information, investment and credit," Journal of International Economics, $76(2), 267-275$. 
Schmitt-Grohe, S., AND M. URIBe (2004): "Solving dynamic general equilibrium models using a second-order approximation to the policy function," Journal of Economic Dynamics and Control, 28(4), 755-775.

Townsend, R. M. (1979): "Optimal contracts and competitive markets with costly state verification," Journal of Economic Theory, 21(2), 265-293.

XU, T. (2012): "The role of credit in international business cycles," Bank of Canada Working Papers 2012-36, Bank of Canada.

YuE, V. Z. (2010): "Sovereign default and debt renegotiation," Journal of International Economics, 80(2), $176-187$. 


\section{A Mathematical Appendix}

\section{A1 Proof of Lemma 1}

Proof. Recall that $\lambda_{i t}$ is independently and identically distributed across $i$ and $t$ and $\lambda_{i t} \sim$ $N\left(0, \sigma_{\lambda}^{2}\right)$. Then

$$
\begin{aligned}
& \int_{-\infty}^{\varpi_{1}-\varepsilon_{t}} e^{\varphi x} f_{\lambda}(x) d x=\int_{-\infty}^{\varpi_{1}-\varepsilon_{t}} \exp (\varphi x) \frac{1}{\sqrt{2 \pi \sigma_{\lambda}^{2}}} \exp \left(-\frac{x^{2}}{2 \sigma_{\lambda}^{2}}\right) d x \\
= & \frac{1}{\sigma_{\lambda}} \int_{-\infty}^{\varpi_{1}-\varepsilon_{t}} \frac{1}{\sqrt{2 \pi}} \exp \left(\varphi x-\frac{x^{2}}{2 \sigma_{\lambda}^{2}}\right) d x \\
= & \frac{1}{\sigma_{\lambda}} \int_{-\infty}^{\varpi_{1}-\varepsilon_{t}} \frac{1}{\sqrt{2 \pi}} \exp \left[-\frac{1}{2 \sigma_{\lambda}^{2}}\left[x^{2}-2 \sigma_{\lambda}^{2} \varphi x+\left(\sigma_{\lambda}^{2} \varphi\right)^{2}\right]+\frac{\sigma_{\lambda}^{2} \varphi^{2}}{2}\right] d x \\
= & \frac{1}{\sigma_{\lambda}} \exp \left(\frac{\sigma_{\lambda}^{2} \varphi^{2}}{2}\right) \int_{-\infty}^{\varpi_{1}-\varepsilon_{t}} \frac{1}{\sqrt{2 \pi}} \exp \left[-\frac{\left(x-\sigma_{\lambda}^{2} \varphi\right)^{2}}{2 \sigma_{\lambda}^{2}}\right] d x .
\end{aligned}
$$

Now let $\varrho=\left(x-\sigma_{\lambda}^{2} \varphi\right) / \sigma_{\lambda}$, then

$$
\begin{aligned}
& \int_{-\infty}^{\varpi_{1}-\varepsilon_{t}} \frac{1}{\sqrt{2 \pi}} \exp \left[-\frac{\left(x-\sigma_{\lambda}^{2} \varphi\right)^{2}}{2 \sigma_{\lambda}^{2}}\right] d x=\int_{-\infty}^{\frac{\varpi_{1}-\varepsilon_{t}-\sigma_{\lambda}^{2} \varphi}{\sigma_{\lambda}}} \frac{1}{\sqrt{2 \pi}} \exp \left(-\frac{\varrho^{2}}{2}\right) \sigma_{\lambda} d \varrho \\
= & \sigma_{\lambda} \Phi\left(\frac{\varpi_{1}-\varepsilon_{t}-\sigma_{\lambda}^{2} \varphi}{\sigma_{\lambda}}\right),
\end{aligned}
$$

where $\Phi(\cdot)$ is the cumulative distribution of a standard normal. Then (A1) becomes

$$
\int_{-\infty}^{\varpi_{1}-\varepsilon_{t}} e^{\varphi x} f_{\lambda}(x) d x=M_{\lambda} \Phi\left(\frac{\varpi_{1}-\varepsilon_{t}-\sigma_{\lambda}^{2} \varphi}{\sigma_{\lambda}}\right)
$$

where $M_{\lambda}=\exp \left(\frac{\sigma_{\lambda}^{2} \varphi^{2}}{2}\right)$ and $\varpi_{1}=\frac{\ln \left(1-\frac{\alpha}{v}\right)}{\varphi}+\frac{\varphi \sigma_{\zeta}^{2}}{2}$ from equations $(2.24)$ and $(2.22)$.

\section{A2 Model Derivation and Solution}

\section{A2.1 Equilibrium conditions in efficiency units}

The system of equations in (3.1) to (3.12) can be further simplified into a nine-equation system in nine unknowns $C_{t}, N_{t}, D_{t}, L_{t}, S_{t}, K_{t}, Y_{t}, R_{l t}$, and $R_{d t}$ by eliminating $W_{t}, \Pi_{t b}$ and $\Pi_{t c}$. As stated earlier, since this model depicts a growing economy where technology grows with a deterministic trend $\mu$, we must scale the endogenous variables $C_{t}, L_{t}, D_{t}, S_{t}, K_{t}, N_{t}$ and $Y_{t}$ in the system of equilibrium conditions by an appropriate factor of technology, $A_{t-1}$, so that they are stationary on a balanced growth path, to guarantee the existence of a steady state in solving the model. We denote the variables in efficiency units by capital letters with a dot, $\dot{C}_{t}=\frac{C_{t}}{A_{t-1}}, \stackrel{\circ}{L}_{t}=\frac{L_{t}}{A_{t-1}}$, $\stackrel{\circ}{S}_{t}=\frac{S_{t}}{A_{t-1}}, \stackrel{\circ}{D}_{t}=\frac{D_{t}}{A_{t-1}}, \stackrel{\circ}{K}_{t}=\frac{K_{t}}{A_{t-1}}, \stackrel{\circ}{N}_{t}=\frac{N_{t}}{A_{t-1}^{1 /(1+\chi)}}, \stackrel{\circ}{Y}_{t}=\frac{Y_{t}}{A_{t-1}}$. 
The equilibrium conditions in efficiency units can be written as

$$
\begin{aligned}
1 & =E\left[\beta\left(\frac{\stackrel{\circ}{C}_{t+1}-\frac{\chi_{0}}{1+\chi} \stackrel{\circ}{N}_{t+1}^{1+\chi}}{\dot{\circ}_{t}-\frac{\chi_{0}}{1+\chi} \stackrel{\circ}{N}_{t}^{1+\chi}}\right)^{-\gamma} g_{t}^{-\gamma} R_{d, t+1} \mid \Omega_{c t}\right], \\
\check{\circ}_{t}-\stackrel{\circ}{C}_{t} & =\stackrel{\circ}{S}_{t}+\stackrel{\circ}{D}_{t+1} g_{t}, \\
\stackrel{\circ}{K}_{t} & =\frac{\alpha \chi_{0}}{1-\alpha} \cdot \frac{\stackrel{\circ}{t}_{t}^{1+\chi}}{R_{l t}}, \\
\stackrel{\circ}{N}_{t} & =\left[\frac{1-\alpha}{\alpha \chi_{0}}\left(\alpha M_{\lambda} M_{\varepsilon}\right)^{\frac{1}{1-\alpha}}\right]^{\frac{1}{\chi}} \exp \left[\frac{\mu\left(1-\rho_{u}\right)}{1+\chi}\right]\left(R_{l t}\right)^{-\frac{\alpha}{(1-\alpha) \chi}} g_{t-1}^{\frac{\rho_{u}}{1+\chi}}, \\
\stackrel{\circ}{Y}_{t} & =M_{\lambda} g_{t}^{\varphi} \stackrel{\circ}{N}_{t}^{1-\alpha} \stackrel{\circ}{K}_{t}^{\alpha}, \\
\stackrel{\circ}{L}_{t} & =\left(1-\frac{1}{v}\right) \stackrel{\circ}{K}_{t}, \stackrel{\circ}{K}_{t}=\stackrel{\circ}{L}_{t}+\stackrel{\circ}{S}_{t}, \stackrel{\circ}{L}_{t}=\theta_{t} \stackrel{\circ}{D}_{t}, \\
R_{d t} \stackrel{\circ}{D}_{t} & =R_{l t} \stackrel{\circ}{L}_{t}(1-\kappa)-\chi_{0}(\kappa-\tau) \stackrel{\circ}{N}_{t}^{1+\chi} .
\end{aligned}
$$

The above system of equations can be further simplified to a system of six equations by eliminating $\stackrel{\circ}{L}_{t}, \stackrel{\circ}{S}_{t}$ and $\stackrel{\circ}{K}_{t}$. The equilibrium conditions in terms of $\stackrel{\circ}{C}_{t}, \stackrel{\circ}{D}_{t}, \stackrel{\circ}{N}_{t}, \stackrel{\circ}{Y}_{t}, R_{d t}$ and $R_{l t}$ are then given by

$$
\begin{aligned}
1 & =E\left[\beta\left(\frac{\stackrel{\circ}{C}_{t+1}-\frac{\chi_{0}}{1+\chi} \stackrel{\circ}{N}_{t+1}^{1+\chi}}{\stackrel{\circ}{t}_{t}-\frac{\chi_{0}}{1+\chi} \stackrel{\circ}{t}^{1+\chi}}\right)^{-\gamma} g_{t}^{-\gamma} R_{d, t+1} \mid \Omega_{c t}\right], \\
\stackrel{\circ}{Y}_{t}-\stackrel{\circ}{C}_{t} & =\frac{1}{v-1} \theta_{t} \stackrel{\circ}{D}_{t}+\stackrel{\circ}{D}_{t+1} g_{t}, \\
\theta_{t} \stackrel{\circ}{D}_{t} & =\frac{\alpha \chi_{0}\left(1-\frac{1}{v}\right)}{1-\alpha} \cdot \frac{\stackrel{\circ}{t}_{t}^{1+\chi}}{R_{l t}}, \\
\stackrel{\circ}{N}_{t} & =\left[\frac{1-\alpha}{\alpha \chi_{0}}\left(\alpha M_{\lambda} M_{\varepsilon}\right)^{\frac{1}{1-\alpha}}\right]^{\frac{1}{\chi}} \exp \left[\frac{\mu\left(1-\rho_{u}\right)}{1+\chi}\right]\left(R_{l t}\right)^{-\frac{\alpha}{(1-\alpha) \chi}} g_{t-1}^{\frac{\rho u}{1+\chi}}, \\
\stackrel{\circ}{Y}_{t} & =M_{\lambda} g_{t}^{\varphi} \stackrel{\circ}{N}_{t}^{1-\alpha}\left[\frac{\theta_{t} \stackrel{\circ}{D}_{t}}{\left(1-\frac{1}{v}\right)}\right]^{\alpha}, \\
R_{d t} \stackrel{\circ}{D}_{t} & =R_{l t} \theta_{t} \stackrel{\circ}{D}_{t}(1-\kappa)-\chi_{0}(\kappa-\tau) \stackrel{\circ}{N}_{t}^{1+\chi} .
\end{aligned}
$$

\section{A2.2 Derivation of the steady states}

We denote the variables in steady states by the lowercase letters with an asterisk, for example, the steady state of consumption is given by ${ }^{\circ}{ }^{*}=E\left(\ln \dot{C}_{t}\right)$ and the steady state of the loan rate is $r_{l}^{*}=E\left(\ln R_{l t}\right) \approx E\left(r_{l t}\right)$. To derive the steady state, we first take logarithms of the equilibrium conditions (A4) to (A6) and then the unconditional expectations of the resulting equations:

$$
\begin{aligned}
E\left(\ln \theta_{t}\right)+\dot{d}^{*} & =\ln \chi_{0}+\ln \left[\frac{\alpha\left(1-\frac{1}{v}\right)}{1-\alpha}\right]+(1+\chi) \dot{n}^{*}-r_{l}^{*}, \\
\dot{n}^{*} & =-\frac{\ln \chi_{0}}{\chi}+\frac{1}{\chi} \ln \left[\frac{1-\alpha}{\alpha}\left(\alpha M_{\lambda} M_{\varepsilon}\right)^{\frac{1}{1-\alpha}}\right]+\frac{\mu}{1+\chi}-\frac{\alpha}{(1-\alpha) \chi} r_{l}^{*}, \\
\dot{y}^{*} & =\ln \left[\frac{M_{\lambda}}{\left(1-\frac{1}{v}\right)^{\alpha}}\right]+\varphi \mu+(1-\alpha) \dot{n}^{*}+\alpha E\left(\ln \theta_{t}\right)+\alpha \dot{d}^{*},
\end{aligned}
$$

since $\ln \left(g_{t}\right)=\mu+u_{t}$ and $E\left(\operatorname{lng}_{t}\right)=\mu$.

To obtain the steady-state conditions for equation (A3), first note that $\stackrel{\circ}{C}_{t}$ can be approximated 
as follows:

$$
\stackrel{\circ}{C}_{t}=e^{\check{c}_{t}} \approx e^{\check{c}^{*}}\left(1+{\stackrel{\tilde{c}_{t}}{t}}_{t},\right.
$$

where $\widetilde{c}_{t}=\stackrel{\circ}{c}_{t}-\stackrel{\stackrel{c}{ }}{*}^{*}$. Equation (A3) can then be approximated by

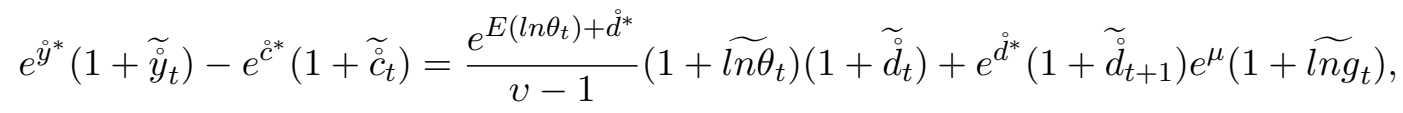

where $\widetilde{\ln g_{t}}=\ln g_{t}-E\left(\ln g_{t}\right)$ and $\widetilde{\ln \theta_{t}}=\ln \theta_{t}-E\left(\ln \theta_{t}\right)$. If we take the unconditional expectations on both sides of the above equation, we have that, in steady state,

$$
e^{\hat{y}^{*}}-e^{\AA^{*}}=e^{\dot{d}^{*}+\mu}+\frac{1}{v-1} e^{E\left(\ln \theta_{t}\right)+\dot{d}^{*}}
$$

Similarly, the steady-state condition for equation (A7) is given by

$$
e^{r_{d}^{*}} e^{\hat{d}^{*}}=e^{r_{l}^{*}+E\left(\ln \theta_{t}\right)+\hat{d}^{*}}(1-\kappa)-\chi_{0}(\kappa-\tau) e^{(1+\chi) \hat{n}^{*}} .
$$

Finally, to derive the steady-state condition for equation (A2), we can approximate $\dot{C}_{t}$ and $\stackrel{\circ}{t}_{t}^{1+\chi}$ as follows:

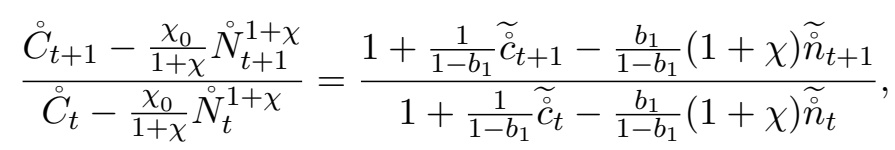

where $b_{1}=\frac{\chi_{0}}{1+\chi} e^{(1+\chi) \grave{n}^{*}-\check{c}^{*}}$. Taking first-order Taylor expansion, we have that following approximation:

$$
\begin{aligned}
& \left(\frac{\stackrel{\circ}{C}_{t+1}-\frac{\chi_{0}}{1+\chi} \stackrel{\circ}{N}_{t+1}^{1+\chi}}{\dot{\circ}_{t}-\frac{\chi_{0}}{1+\chi} \stackrel{\circ}{N}_{t}^{1+\chi}}\right)^{-\gamma} \\
\approx & 1-\frac{\gamma}{1-b_{1}} \stackrel{\widetilde{c}}{t+1}_{t}+\frac{b_{1} \gamma}{1-b_{1}}(1+\chi) \widetilde{\tilde{n}}_{t+1}+\frac{\gamma}{1-b_{1}} \widetilde{\widetilde{c}}_{t}-\frac{b_{1} \gamma}{1-b_{1}}(1+\chi) \widetilde{\widetilde{n}}_{t} .
\end{aligned}
$$

Furthermore, we can approximate $g_{t}^{-\gamma} R_{d, t+1}$ in equation (A2) as follows:

$$
g_{t}^{-\gamma} R_{d, t+1} \approx b_{2}\left(1-\gamma \widetilde{\ln g_{t}}+\widetilde{r}_{d, t+1}\right)
$$

where $b_{2}=e^{-\gamma \mu+r_{d}^{*}}$. Therefore, equation (A2) is approximated by

$$
\frac{1}{\beta b_{2}}-1=E\left[-\frac{\gamma}{1-b_{1}}\left(\widetilde{\tilde{c}}_{t+1}-\widetilde{\tilde{c}}_{t}\right)+\frac{b_{1} \gamma(1+\chi)}{1-b_{1}}\left(\widetilde{\widetilde{n}}_{t+1}-\widetilde{\tilde{n}}_{t}\right)-\gamma \widetilde{\ln g}_{t}+\widetilde{r}_{d, t+1} \mid \Omega_{c t}\right] .
$$

Now, if we take the unconditional expectations on both sides of (A8), by the law of iterated expectations, the right hand side of equation (A8) is equal to zero. In steady state, we then have $\beta b_{2}=1$, which together with $b_{2}=e^{-\gamma \mu+r_{d}^{*}}$, we obtain $r_{d}^{*}=\gamma \mu-\ln \beta$.

\section{A2.3 Log-linearization}

We log-linearize the system of equilibrium equations around the steady state of the log of the variables and denote the variables with a tilde, e.g. $\widetilde{c}_{t}=\stackrel{\circ}{c}_{t}-\stackrel{\circ}{c}^{*}$. Note again that $\dot{C}_{t}$ can be approximated as $\stackrel{\circ}{C}_{t}=e^{\check{c}_{t}} \approx e^{\AA^{*}}\left(1+\widetilde{\stackrel{c}{c}}_{t}\right)$. For equations (A4) to (A6), the log approximations are 
given by

$$
\begin{aligned}
& \widetilde{\ln \theta_{t}}+{\widetilde{\tilde{d}_{t}}+\widetilde{r}_{l t}}=(1+\chi) \widetilde{\tilde{n}}_{t} \\
& \widetilde{\tilde{n}}_{t}=-\frac{\alpha}{(1-\alpha) \chi} \widetilde{r}_{l t}+\frac{\rho_{u}}{1+\chi} \widetilde{\ln g_{t-1}} \\
& \widetilde{\dot{y}}=\varphi \widetilde{\ln g_{t}}+(1-\alpha) \widetilde{\tilde{n}}_{t}+\alpha \widetilde{\ln \theta_{t}}+\alpha \widetilde{\mathfrak{d}}_{t} .
\end{aligned}
$$

For equation (A3), it can be approximated by

$$
\begin{aligned}
& e^{\check{y}^{*}}\left(1+\widetilde{\mathscr{y}}_{t}\right)-e^{\tilde{c}^{*}}\left(1+\widetilde{\check{c}}_{t}\right)
\end{aligned}
$$

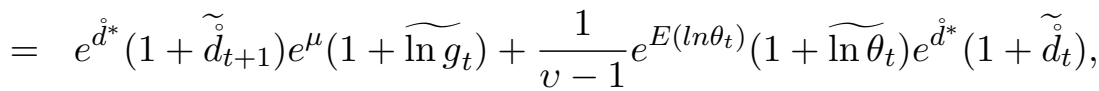

while in the steady state,

$$
e^{\hat{y}^{*}}-e^{\tilde{c}^{*}}=e^{\dot{d}^{*}+\mu}+\frac{1}{v-1} e^{E\left(\ln \theta_{t}\right)+\dot{d}^{*}} .
$$

The log approximation is then given by

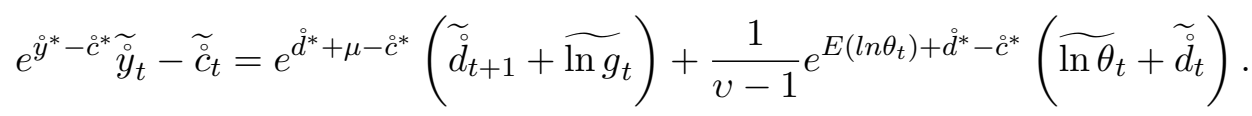

Similarly, the log-linearized approximation for equation (A7) is given by

$$
\begin{aligned}
& e^{r_{d}^{*}+\mathscr{d}^{*}}\left(\widetilde{r}_{d t}+\widetilde{\stackrel{d}{d}}_{t}\right) \\
= & e^{r_{l}^{*}+E\left(\ln \theta_{t}\right)+\dot{d}^{*}}(1-\kappa)\left(\widetilde{r}_{l t}+\widetilde{\stackrel{d}{d}}_{t}+\widetilde{\ln \theta_{t}}\right)-\chi_{0}(\kappa-\tau)(1+\chi) e^{(1+\chi) \dot{n}^{*}} \widetilde{\widetilde{n}}_{t} .
\end{aligned}
$$

Finally, to log-linearize equation (A2), first recall that it can be approximated by equation (A8). Note that $\frac{1}{\beta b_{2}}-1=0$ in steady state, and we have the following log approximation:

$$
{\widetilde{c_{c}}}_{t}-b_{1}(1+\chi) \widetilde{\tilde{n}}_{t}=E\left[\widetilde{\stackrel{c}{c}}_{t+1}-b_{1}(1+\chi){\widetilde{\tilde{n}_{t+1}}}_{t}+\left(1-b_{1}\right) \widetilde{\ln g}{ }_{t}-\frac{1-b_{1}}{\gamma} \widetilde{r}_{d, t+1} \mid \Omega_{c t}\right] .
$$

The log-linearized approximation of the equilibrium conditions of the model are therefore, noting $\widetilde{\ln g} g_{t}=u_{t}$,

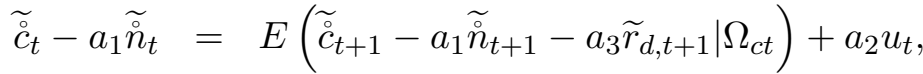

$$
\begin{aligned}
& -\widetilde{c}_{t}+a_{5} \widetilde{\mathscr{y}}_{t}-a_{6}{\widetilde{\widetilde{d}_{t+1}}}_{t+1}=a_{4} \widetilde{\stackrel{d}{d}}_{t}+a_{6} u_{t}+a_{4} \widetilde{\ln \theta} t \\
& \widetilde{\tilde{n}}_{t}+\frac{\alpha}{(1-\alpha) \chi} \widetilde{r}_{l t}=\frac{\rho_{u}}{1+\chi} u_{t-1}, \\
& a_{9} \widetilde{\tilde{n}}_{t}+a_{7} \widetilde{r}_{d t}-a_{8} \widetilde{r}_{l t}=-\left(a_{7}-a_{8}\right) \widetilde{\stackrel{o}{d}}_{t}+a_{8} \widetilde{\ln \theta_{t}}, \\
& \widetilde{\mathscr{y}}_{t}-(1-\alpha){\widetilde{\tilde{n}_{t}}}_{t}=\alpha \widetilde{\stackrel{d}{d}}_{t}+\varphi u_{t}+\alpha \widetilde{\ln \theta_{t}}, \\
& (1+\chi) \widetilde{\tilde{n}}_{t}-\widetilde{r}_{l t}=\widetilde{\stackrel{o}{d}}_{t}+\widetilde{\ln \theta_{t}} \text {, }
\end{aligned}
$$


where

$$
\begin{aligned}
& a_{1}=b_{1}(1+\chi), a_{2}=1-b_{1}, a_{3}=\frac{1-b_{1}}{\gamma}, \\
& a_{4}=\frac{1}{v-1} e^{E\left(\ln \theta_{t}\right)+\dot{d}^{*}-\dot{c}^{*}}, a_{5}=e^{\dot{y}^{*}-\dot{c}^{*}}, a_{6}=e^{\dot{d}^{*}+\mu-\tilde{c}^{*}}, \\
& a_{7}=e^{r_{d}^{*}+\dot{d}^{*}}, a_{8}=e^{r_{l}^{*}+E\left(\ln \theta_{t}\right)+\dot{d}^{*}}(1-\kappa), \\
& a_{9}=\chi_{0}(\kappa-\tau)(1+\chi) e^{(1+\chi) \tilde{n}^{*}}, b_{1}=\frac{\chi_{0}}{1+\chi} e^{(1+\chi) \tilde{n}^{*}-\dot{c}^{*}} .
\end{aligned}
$$

Using the expressions for $a_{4}, a_{5}, a_{6}, a_{7}, a_{8}$ and $a_{9}$ above, the steady-state conditions (3.25) and (3.27) can be re-written as

$$
a_{5}=1+a_{4}+a_{6}, a_{9}=(1+\chi)\left(a_{8}-a_{7}\right), \text { respectively. }
$$

Note also that the above system of equations can be simplified by substituting $\widetilde{\stackrel{d}{d}}_{t}$ from equation (A14) in equations (A12) and (A13). The log-linearized equations (A10), (A12) and (A13) can then be re-written as the expressions in the main body of the paper.

\section{A2.4 Model solution}

We use the quadratic determinantal equation (QDE) approach of Binder and Pesaran $(1995,1997)$

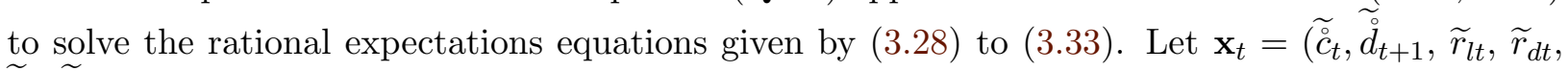
$\left.\widetilde{\stackrel{y}{y}}_{t}, \widetilde{\grave{n}}_{t}\right)^{\prime}$, and the above system of equations are written as

$$
\mathbf{H}_{0} \mathbf{x}_{t}=\mathbf{H}_{1} \mathbf{x}_{t-1}+\mathbf{H}_{\mathbf{2}} E\left(\mathbf{x}_{t+1} \mid \Omega_{t}\right)+\mathbf{v}_{t},
$$

where

$$
\mathbf{v}_{t}=\tilde{\mathbf{G}}_{0} \boldsymbol{\xi}_{t}+\tilde{\mathbf{G}}_{1} \boldsymbol{\xi}_{t-1}, \quad \boldsymbol{\xi}_{t}=\left(\frac{u_{t}}{\ln \theta_{t}}\right)
$$

and

$$
\boldsymbol{\xi}_{t}=\mathbf{R} \boldsymbol{\xi}_{t-1}+\boldsymbol{\psi}_{t}, \quad \mathbf{R}=\left(\begin{array}{cc}
\rho_{u} & 0 \\
0 & \rho_{\theta}
\end{array}\right), \quad \boldsymbol{\psi}_{t}=\left(\begin{array}{c}
\varepsilon_{t} \\
\widetilde{\eta}_{t}
\end{array}\right)
$$

with $\varepsilon_{t} \sim \mathbb{N}\left(0, \sigma_{\varepsilon}^{2}\right)$, and $\widetilde{\eta}_{t} \sim \mathbb{N}\left(0, \sigma_{\eta}^{2}\right)$.

The matrices $\mathbf{H}_{0}, \mathbf{H}_{1}, \mathbf{H}_{2}, \tilde{\mathbf{G}}_{0}, \tilde{\mathbf{G}}_{1}$ and $\mathbf{x}_{t}$ are given by

$$
\begin{aligned}
\mathbf{H}_{0} & =\left(\begin{array}{cccccc}
1 & 0 & 0 & 0 & 0 & -a_{1} \\
-1 & -a_{6} & 0 & 0 & 1+a_{4}+a_{6} & 0 \\
0 & 0 & \frac{\alpha}{(1-\alpha) \chi} & 0 & 0 & 1 \\
0 & 0 & -1 & 1 & 0 & 0 \\
0 & 0 & \alpha & 0 & 1 & -(1+\alpha \chi) \\
0 & 0 & -1 & 0 & 0 & (1+\chi)
\end{array}\right), \mathbf{H}_{1}=\left(\begin{array}{cccccc}
0 & 0 & 0 & 0 & 0 & 0 \\
0 & a_{4} & 0 & 0 & 0 & 0 \\
0 & 0 & 0 & 0 & 0 & 0 \\
0 & 0 & 0 & 0 & 0 & 0 \\
0 & 0 & 0 & 0 & 0 & 0 \\
0 & 1 & 0 & 0 & 0 & 0
\end{array}\right), \\
\mathbf{H}_{2} & =\left(\begin{array}{cccccc}
1 & 0 & 0 & -a_{3} & 0 & -a_{1} \\
0 & 0 & 0 & 0 & 0 & 0 \\
0 & 0 & 0 & 0 & 0 & 0 \\
0 & 0 & 0 & 0 & 0 & 0 \\
0 & 0 & 0 & 0 & 0 & 0 \\
0 & 0 & 0 & 0 & 0 & 0
\end{array}\right), \tilde{\mathbf{G}}_{0}=\left(\begin{array}{cc}
a_{2} & 0 \\
a_{6} & a_{4} \\
0 & 0 \\
0 & 1 \\
\varphi & 0 \\
0 & 1
\end{array}\right), \tilde{\mathbf{G}}_{1}=\left(\begin{array}{cc}
0 & 0 \\
0 & 0 \\
\frac{\rho_{u}}{1+\chi} & 0 \\
0 & 0 \\
0 & 0 \\
0 & 0
\end{array}\right), \mathbf{x}_{t}=\left(\begin{array}{c}
\widetilde{c}_{t} \\
\widetilde{\circlearrowleft}_{t+1} \\
\widetilde{r}_{l t} \\
\widetilde{r}_{d t} \\
\widetilde{⿳}_{t} \\
\widetilde{\tilde{n}}_{t}
\end{array}\right) .
\end{aligned}
$$

Note that $\boldsymbol{\psi}_{t}$ is a serially uncorrelated vector process with zero mean. Note also that $\mathbf{H}_{0}$ is nonsingular, and using equation (A16), (A15) can be written as

$$
\mathbf{x}_{t}=\mathbf{H}_{0}^{-1} \mathbf{H}_{1} \mathbf{x}_{t-1}+\mathbf{H}_{0}^{-1} \mathbf{H}_{2} E\left(\mathbf{x}_{t+1} \mid \Omega_{t}\right)+\mathbf{H}_{0}^{-1} \tilde{\mathbf{G}}_{0} \boldsymbol{\xi}_{t}+\mathbf{H}_{0}^{-1} \tilde{\mathbf{G}}_{1} \boldsymbol{\xi}_{t-1},
$$


or

$$
\mathbf{x}_{t}=\mathbf{A} \mathbf{x}_{t-1}+\mathbf{B} E\left(\mathbf{x}_{t+1} \mid \Omega_{t}\right)+\mathbf{G}_{0} \boldsymbol{\xi}_{t}+\mathbf{G}_{1} \boldsymbol{\xi}_{t-1},
$$

where $\mathbf{A}=\mathbf{H}_{0}^{-1} \mathbf{H}_{1}, \mathbf{B}=\mathbf{H}_{0}^{-1} \mathbf{H}_{2}, \mathbf{G}_{0}=\mathbf{H}_{0}^{-1} \tilde{\mathbf{G}}_{0}$, and $\mathbf{G}_{1}=\mathbf{H}_{0}^{-1} \tilde{\mathbf{G}}_{1}$.

The rational expectations solution of (A18) is given by ${ }^{29}$

$$
\mathbf{x}_{t}=\mathbf{C x}_{t-1}+\mathbf{D}_{0} \boldsymbol{\xi}_{t}+\mathbf{D}_{1} \boldsymbol{\xi}_{t-1}
$$

where

$$
\begin{aligned}
\mathbf{B C}^{2}-\mathbf{C}+\mathbf{A} & =\mathbf{0} \\
\mathbf{D}_{1} & =(\mathbf{I}-\mathbf{B C})^{-1} \mathbf{G}_{1} \\
(\mathbf{I}-\mathbf{B C}) \mathbf{D}_{\mathbf{0}}-\mathbf{B D}_{0} \mathbf{R} & =\mathbf{G}_{0}+\mathbf{B}(\mathbf{I}-\mathbf{B C})^{-\mathbf{1}} \mathbf{G}_{1}
\end{aligned}
$$

Following Binder and Pesaran (1995, 1997), we use the quadratic determinantal equation (QDE) in (A20) to solve for $\mathbf{C}$. After obtaining $\mathbf{C}$, (A21) can be used to obtain $\mathbf{D}_{1}$. To solve for $\mathbf{D}_{0}$, first write equation (A22) as

$$
\mathbf{D}_{0}-\mathbf{Q}_{0} \mathbf{D}_{0} \mathbf{R}=\mathbf{Q}_{1}
$$

where

$$
\begin{aligned}
& \mathbf{Q}_{0}=(\mathbf{I}-\mathbf{B C})^{-1} \mathbf{B} \\
& \mathbf{Q}_{1}=(\mathbf{I}-\mathbf{B C})^{-1} \mathbf{G}_{0}+(\mathbf{I}-\mathbf{B C})^{-1} \mathbf{B}(\mathbf{I}-\mathbf{B C})^{-\mathbf{1}} \mathbf{G}_{\mathbf{1}}
\end{aligned}
$$

Then, using results in Magnus and Neudecker (1988) (pp. 30-31), we find

$$
\operatorname{vec}\left(\mathbf{D}_{0}\right)-\left(\mathbf{R}^{\prime} \otimes \mathbf{Q}_{0}\right) \operatorname{vec}\left(\mathbf{D}_{0}\right)=\operatorname{vec}\left(\mathbf{Q}_{1}\right),
$$

which yields

$$
\operatorname{vec}\left(\mathbf{D}_{0}\right)=\left[\mathbf{I}-\left(\mathbf{R}^{\prime} \otimes \mathbf{Q}_{0}\right)\right]^{-1} \operatorname{vec}\left(\mathbf{Q}_{1}\right)
$$

\section{A2.5 Solution of the Canonical Rational Expectations model}

Proof. We show that $\mathbf{x}_{t}=\mathbf{C x}_{t-1}+\mathbf{D}_{0} \boldsymbol{\xi}_{t}+\mathbf{D}_{1} \boldsymbol{\xi}_{t-1}$ is indeed a solution of

$$
\mathbf{x}_{t}=\mathbf{A} \mathbf{x}_{t-1}+\mathbf{B} E\left(\mathbf{x}_{t+1} \mid \Omega_{t}\right)+\mathbf{G}_{0} \boldsymbol{\xi}_{t}+\mathbf{G}_{1} \boldsymbol{\xi}_{t-1} .
$$

First, note that the left-hand side of (A24) can be written as

$$
\begin{aligned}
\mathbf{x}_{t} & =\mathbf{C} \mathbf{x}_{t-1}+\mathbf{D}_{0} \boldsymbol{\xi}_{t}+\mathbf{D}_{1} \boldsymbol{\xi}_{t-1} \\
& =\mathbf{C}\left(\mathbf{C x}_{t-2}+\mathbf{D}_{0} \boldsymbol{\xi}_{t-1}+\mathbf{D}_{1} \boldsymbol{\xi}_{t-2}\right)+\mathbf{D}_{0} \boldsymbol{\xi}_{t}+\mathbf{D}_{1} \boldsymbol{\xi}_{t-1} \\
& =\mathbf{C}^{2} \mathbf{x}_{t-2}+\mathbf{D}_{0} \boldsymbol{\xi}_{t}+\left(\mathbf{C D}_{0}+\mathbf{D}_{1}\right) \boldsymbol{\xi}_{t-1}+\mathbf{C D}_{1} \boldsymbol{\xi}_{t-2}
\end{aligned}
$$

To evaluate the right-hand side of (A24), note that

$$
\begin{aligned}
& E\left(\mathbf{x}_{t+1} \mid \Omega_{t}\right)=E\left(\mathbf{C x}_{t}+\mathbf{D}_{0} \boldsymbol{\xi}_{t+1}+\mathbf{D}_{1} \boldsymbol{\xi}_{t} \mid \Omega_{t}\right) \\
& =\mathbf{C x}_{t}+\mathbf{D}_{0} E\left(\boldsymbol{\xi}_{t+1} \mid \Omega_{t}\right)+\mathbf{D}_{1} \boldsymbol{\xi}_{t} \\
& =\mathbf{C}\left(\mathbf{C x}_{\mathrm{t}-\mathbf{1}}+\mathbf{D}_{\mathbf{0}} \boldsymbol{\xi}_{\mathrm{t}}+\mathbf{D}_{1} \boldsymbol{\xi}_{\mathrm{t}-\mathbf{1}}\right)+\mathbf{D}_{\mathbf{0}} \mathbf{R} \boldsymbol{\xi}_{\mathrm{t}}+\mathbf{D}_{1} \boldsymbol{\xi}_{t} \\
& =\mathbf{C}^{2} \mathbf{x}_{t-1}+\left(\mathbf{C D}_{\mathbf{0}}+\mathbf{D}_{\mathbf{0}} \mathbf{R}+\mathbf{D}_{1}\right) \boldsymbol{\xi}_{t}+\mathbf{C D}_{\mathbf{1}} \boldsymbol{\xi}_{t-1} \\
& =\mathbf{C}^{2}\left(\mathbf{C x}_{t-2}+\mathbf{D}_{0} \boldsymbol{\xi}_{t-1}+\mathbf{D}_{1} \boldsymbol{\xi}_{t-2}\right)+\left(\mathbf{C D}_{\mathbf{0}}+\mathbf{D}_{\mathbf{0}} \mathbf{R}+\mathbf{D}_{1}\right) \boldsymbol{\xi}_{t}+\mathbf{C D}_{\mathbf{1}} \boldsymbol{\xi}_{t-1} \\
& =\mathbf{C}^{3} \mathbf{x}_{t-2}+\left(\mathbf{C D}_{\mathbf{0}}+\mathbf{D}_{\mathbf{0}} \mathbf{R}+\mathbf{D}_{1}\right) \boldsymbol{\xi}_{t}+\left(\mathbf{C}^{2} \mathbf{D}_{0}+\mathbf{C D}_{\mathbf{1}}\right) \boldsymbol{\xi}_{t-1}+\mathbf{C}^{2} \mathbf{D}_{1} \boldsymbol{\xi}_{t-2} .
\end{aligned}
$$

\footnotetext{
${ }^{29}$ The proof that (A19) is indeed a solution to (A18) is given in the Appendix A2.5.
} 
Therefore, the right-hand side of (A24) is given by

$$
\begin{aligned}
& \mathbf{A} \mathbf{x}_{t-1}+\mathbf{B} E\left(\mathbf{x}_{t+1} \mid \Omega_{t}\right)+\mathbf{G}_{0} \boldsymbol{\xi}_{t}+\mathbf{G}_{1} \boldsymbol{\xi}_{t-1} \\
& =\mathbf{A}\left(\mathbf{C x}_{t-2}+\mathbf{D}_{\mathbf{0}} \boldsymbol{\xi}_{t-1}+\mathbf{D}_{\mathbf{1}} \boldsymbol{\xi}_{t-2}\right)+\mathbf{B} E\left(\mathbf{x}_{t+1} \mid \Omega_{t}\right)+\mathbf{G}_{0} \boldsymbol{\xi}_{t}+\mathbf{G}_{1} \boldsymbol{\xi}_{t-1} \\
& =\mathbf{A}\left(\mathbf{C x}_{t-2}+\mathbf{D}_{\mathbf{0}} \boldsymbol{\xi}_{t-1}+\mathbf{D}_{\mathbf{1}} \boldsymbol{\xi}_{t-2}\right)+\mathbf{G}_{0} \boldsymbol{\xi}_{t}+\mathbf{G}_{1} \boldsymbol{\xi}_{t-1} \\
& +\mathbf{B C}^{3} \mathbf{x}_{t-2}+\left(\mathbf{B C D}_{\mathbf{0}}+\mathbf{B D}_{\mathbf{0}} \mathbf{R}+\mathbf{B D}_{1}\right) \boldsymbol{\xi}_{t}+\left(\mathbf{B C}^{2} \mathbf{D}_{0}+\mathbf{B C D}_{\mathbf{1}}\right) \boldsymbol{\xi}_{t-1}+\mathbf{B C}^{2} \mathbf{D}_{1} \boldsymbol{\xi}_{t-2} \\
& =\left(\mathbf{A C}+\mathbf{B C}^{3}\right) \mathbf{x}_{t-2}+\left(\mathbf{G}_{0}+\mathbf{B C D}_{\mathbf{0}}+\mathbf{B D}_{\mathbf{0}} \mathbf{R}+\mathbf{B D}_{1}\right) \boldsymbol{\xi}_{t} \\
& +\left(\mathbf{A D}_{\mathbf{0}}+\mathbf{G}_{1}+\mathbf{B C}^{2} \mathbf{D}_{0}+\mathbf{B C D} \mathbf{D}_{\mathbf{1}}\right) \boldsymbol{\xi}_{t-1}+\left(\mathbf{A D}_{\mathbf{1}}+\mathbf{B C}^{2} \mathbf{D}_{1}\right) \boldsymbol{\xi}_{t-2} .
\end{aligned}
$$

Equating the coefficients of $\mathbf{x}_{t-2}, \boldsymbol{\xi}_{t}, \boldsymbol{\xi}_{t-1}$ and $\boldsymbol{\xi}_{t-2}$ on both sides of (A24), we have

$$
\begin{aligned}
& \mathbf{x}_{t-2}: \mathbf{C}^{2}=\mathbf{A} \mathbf{C}+\mathbf{B C}^{3}, \\
& \boldsymbol{\xi}_{t}: \mathbf{D}_{0}=\mathbf{G}_{0}+\mathbf{B C D}_{\mathbf{0}}+\mathbf{B D}_{\mathbf{0}} \mathbf{R}+\mathbf{B D}_{1} \text {, } \\
& \boldsymbol{\xi}_{t-1}: \mathbf{C D}_{0}+\mathbf{D}_{1}=\mathbf{A D}_{\mathbf{0}}+\mathbf{G}_{1}+\mathbf{B C}^{2} \mathbf{D}_{0}+\mathbf{B C D} \text {, } \\
& \boldsymbol{\xi}_{t-2}: \mathbf{C D}_{1}=\mathbf{A} \mathbf{D}_{\mathbf{1}}+\mathbf{B C}^{2} \mathbf{D}_{1} \text {. }
\end{aligned}
$$

The above conditions can be simplified to

$$
\begin{aligned}
\mathbf{B C}^{2}+\mathbf{A}-\mathbf{C} & =0, \mathbf{D}_{1}=(\mathbf{I}-\mathbf{B C})^{-1} \mathbf{G}_{1}, \\
(\mathbf{I}-\mathbf{B C}) \mathbf{D}_{0}-\mathbf{B} \mathbf{D}_{0} \mathbf{R} & =\mathbf{G}_{0}+\mathbf{B D}_{1}
\end{aligned}
$$

that is,

$$
(\mathbf{I}-\mathbf{B C}) \mathbf{D}_{\mathbf{0}}-\mathbf{B D}_{0} \mathbf{R}=\mathbf{G}_{0}+\mathbf{B}(\mathbf{I}-\mathbf{B C})^{-1} \mathbf{G}_{1},
$$

which is the solution given by (A19).

\section{A2.6 Impulse responses}

We compute the impulse responses to a credit shock following Koop, Pesaran, and Potter (1996) and Pesaran and Shin (1998), since the generalized impulse response functions offer more modelling flexibility.

Definition 1 The "generalized impulse response function"(GIRF) of a vector process $\mathbf{x}_{t}$ of dimension $p \times 1$ is defined by

$$
G I_{\mathbf{x}}\left(h, \delta, \Omega_{t-1}\right)=E\left(\mathbf{x}_{t+h} \mid \boldsymbol{\psi}_{t}=\delta, \Omega_{t-1}\right)-E\left(\mathbf{x}_{t+h} \mid \Omega_{t-1}\right),
$$

where $\Omega_{t-1}$ is the common information set at time $t-1$, and $\delta$ is a vector of shocks.

Recall that model solutions are given by equation (A19). Using definition 1 of GIRFs and denoting $G I_{\mathbf{x}}\left(h, \delta, \Omega_{t-1}\right)$ by $G I_{\mathbf{x}}(h)$ for simplicity, we have:

$$
\begin{aligned}
& G I_{\mathbf{x}}(h)=\mathbf{C} G I_{\mathbf{x}}(h-1)+\mathbf{D}_{0} G I_{\xi}(h)+\mathbf{D}_{1} G I_{\xi}(h-1), \text { for } h=0,1,2,3 \ldots \\
& G I_{\xi}(h)=\mathbf{R} G I_{\xi}(h-1), \text { for } h=1,2,3 \ldots, \\
& G I_{\mathbf{x}}(h)=0, \text { for } h<0, \text { and } G I_{\xi}(h)=0, \text { for } h<0
\end{aligned}
$$

For the technology shock on impact, we have

$$
G I_{\xi}(0)=G I_{\psi}(0)=\frac{1}{\sqrt{\mathbf{e}_{1}^{\prime} \operatorname{Cov}\left(\boldsymbol{\psi}_{t}\right) \mathbf{e}_{1}}} \operatorname{Cov}\left(\boldsymbol{\psi}_{t}\right) \mathbf{e}_{1},
$$


where $\mathbf{e}_{1}=(1,0)^{\prime}$ and

$$
\operatorname{Cov}\left(\psi_{t}\right)=\left(\begin{array}{cc}
\sigma_{\varepsilon}^{2} & \rho_{\varepsilon \eta} \sigma_{\varepsilon} \sigma_{\eta} \\
\rho_{\varepsilon \eta} \sigma_{\varepsilon} \sigma_{\eta} & \sigma_{\eta}^{2}
\end{array}\right)
$$

To obtain the GIRFs for the credit shock, we need to replace $\mathbf{e}_{1}$ in (A25) by $\mathbf{e}_{2}=(0,1)^{\prime}$. In the standard case where technology shocks and credit shocks are assumed to be uncorrelated, we have

$$
\operatorname{Cov}\left(\boldsymbol{\psi}_{t}\right)=\left(\begin{array}{cc}
\sigma_{\varepsilon}^{2} & 0 \\
0 & \sigma_{\eta}^{2}
\end{array}\right)
$$

and (A25) can be simplified such that $G I_{\xi}(0)=\left(\sigma_{\varepsilon}, 0\right)^{\prime}$ for a one-standard-deviation positive shock to technology, and $G I_{\xi}(0)=\left(0, \sigma_{\eta}\right)^{\prime}$ for a one-standard-deviation positive shock to credit.

Also, recalling that $L_{t}=\theta_{t} D_{t}$, then $\widetilde{\grave{l}}_{t}=\widetilde{\ln }_{t}+\widetilde{\stackrel{d}{d}}_{t}$, and the GIRF of $\widetilde{\stackrel{l}{l}}_{t}$ is given by

$$
G I_{l}(h)=G I_{\ln \theta}(h)+G I_{d}(h-1),
$$

where $G I_{\ln \theta}(h)$ is defined by the second element of $G I_{\xi}(h)$, or $(0,1) G I_{\xi}(h)$, and $G I_{d}(h-1)$ is given by the second element of $G I_{\mathbf{x}}(h) \cdot{ }^{30}$

In log-linearized form, labour productivity is given by $\widetilde{\operatorname{prod}}_{t}=\widetilde{\stackrel{y}{y}}_{t}-\widetilde{\tilde{n}}_{t}$, and therefore, the GIRF for $\widetilde{p r o d}_{t}$ can be computed as

$$
G I_{\text {prod }}(h)=G I_{y}(h)-G I_{n}(h),
$$

where $G I_{y}(h)$ and $G I_{n}(h)$ are given by the fifth and the sixth elements of $G I_{\mathbf{x}}(h)$, respectively.

\section{B Data Appendix}

\section{B1 Data sources}

The main sources of the time-series data are Datastream and the Federal Reserve.

\section{B1.1 Deposit rate}

The Datastream series "U.S. CD Secondary Market 1 Month - Middle Rate" (FRCDS1M), "U.S. CD Secondary Market 3 Month - Middle Rate" (FRCDS3M), "U.S. CD Secondary Market 6 Month - Middle Rate" (FRCDS6M) are used to construct the deposit rate series used in the paper. The deposit rate is given by the arithmetic average of the one-month, three-month and six-month certificate of deposit (CD) series. The source for the Datastream series is the Federal Reserve and the series are measured in per cent per annum. The middle rate refers to the midpoint between the bid and offered rates.

We decided to use the Datastream (Federal Reserve) series instead of the International Finance Statistics series "U.S. Certificate of Deposit rate 3 months (secondary market)" (60LC.ZF), since the Federal Reserve has a broader coverage of CD rates, to include the one-month and six-month $\mathrm{CD}$ rates, which we use to construct the final deposit-rate series.

\section{B1.2 Loan rate}

We take the Datastream series "U.S. Bank Prime Loan - Middle Rate" (FRBKPRM) as our preferred measure of the loan rate. The source of this series is the Federal Reserve. The U.S. Bank Prime Loan Rate is the rate posted by a majority of top 25 (by assets in domestic offices) insured U.S. chartered commercial banks. Prime is one of the several base rates used by banks

\footnotetext{
${ }^{30}$ Note that the second element of $G I_{\mathbf{x}}(h)$ refers to the GIRF of $\widetilde{\stackrel{d}{d}}_{t+1}$, which is given by $G I_{d}(h)$, and therefore the associate GIRF for $\widetilde{\stackrel{d}{d}}_{t}$ is $G I_{d}(h-1)$.
} 
to price short-term business loans. Weekly figures are averages of the seven calendar days ending on Wednesday of the current week; monthly figures include each calendar day in the month. The interest rate is annualized using bank interest, and the middle rate refers to the midpoint between the bid and offered rates. We decided to use the Datastream (Federal Reserve) series instead of the IFS series "Bank prime loan rate" (60P..ZF) to be consistent with the source of our deposit-rate series.

\section{B1.3 CPI series}

Note that, both the series for the loan rate and deposit rate are in nominal terms. In order to estimate our model, we need to convert the nominal loan and deposit rates to real series, using a measure of the inflation rate. We take the CPI series "Consumer Price Index for All Urban Consumers: All Items" from the Federal Reserve Bank of St Louis (CPIAUCSL). The series is seasonally adjusted and indexed at the years 1982-84 (=100).

\section{B1.4 Consumption}

We use the data series "U.S. Real Personal Consumption Expenditures" (PCECC96) from Federal Reserve Bank of St Louis as our measure for consumption. The data source is U.S. Department of Commerce: Bureau of Economic Analysis, and the quarterly series is seasonally adjusted in billions of chained 2005 dollars.

\section{B1.5 Output}

The gross domestic product series is taken from the Federal Reserve Bank of St Louis (GDPC96). The series is seasonally adjusted in billions of chained 2005 dollars.

\section{B1.6 Bank deposits}

We use the Federal Reserve series "U.S. commercial bank liabilities-deposits and borrowing" (Federal Reserve H.8 Table) as a measure of bank deposits. This series is measured in billions of U.S. dollars and current prices, and is seasonally adjusted. According to the Federal Reserve, www.federalreserve.gov/releases/h8/current/default.htm (page 3), deposits are composed of large time deposits and other deposits.

\section{B1.7 Bank credit}

The data series on bank credit ("U.S. Commercial bank assets-bank credit") is taken from the Federal Reserve H.8 Table, http://www.federalreserve.gov/releases/h8/current/default.htm (page 2). According to the Federal Reserve, bank credit is composed of securities in bank credit, and loans and leases in bank credit. Loans and leases in bank credit include commercial and industrial loans, real estate loans and consumer loans. We use the credit series from the Federal Reserve, rather than the IFS measure "Bank credit to the private sector" used in the empirical paper, because there is no matching deposit series from the IFS, while such series exists in the Federal Reserve. The data series on bank credit is seasonally adjusted and expressed in billions of dollars in current prices.

\section{B1.8 Wages}

The Federal Reserve series on "Average Hourly Earnings of Production and Nonsupervisory Employees: Total Private" is used as a proxy for wages. The data source is the Federal Reserve Bank of St Louis (AHETPI), taken from the U.S. Department of Labor: Bureau of Labor Statistics. The data series is seasonally adjusted and expressed in dollars per hour. 


\section{B1.9 Hours worked}

The data series on "Average Weekly Hours Private Non-Farm United States" is taken from Datastream (USHKIP..O). The primary source of the data is the U.S. Department of Labor: Bureau of Labor Statistics (USDOL). The series is measured in hours and seasonally adjusted. It captures the expected or actual period of employment for the week, usually expressed in the number of hours.

\section{B1.10 Employment}

The employment data ("All Employees: Total Private Industries") are from the Federal Reserve Bank of St Louis (USPRIV). The series is measured in thousands of persons and seasonally adjusted. The source of the data is the U.S. Department of Labor: Bureau of Labor Statistics.

\section{B1.11 U.S. population}

The U.S. population data ("U.S. Population: Mid-Month") are from the Federal Reserve Bank of St Louis (POPTHM). The series is measured in thousands. The source is the U.S. Department of Commerce: Bureau of Economic Analysis.

\section{B1.12 Liabilities of non-financial non-farm corporate business}

We take the Federal Reserve Flow of Funds series (levels data, Table L.102) on the liabilities of nonfinancial non-farm corporate business. In particular, we are interested in the series on corporate bonds (Z1/FL103163003.Q), corporate equities (Z1/FL103164103), and loans and short-term paper (Z1/FL104140005.Q). The series are measured in millions of U.S. dollars.

The data series are available upon request. 


\section{Empirical evidence of time-varying volatility}

In order to examine the empirical evidence of time-varying volatility in the U.S. credit and output data, we estimate GARCH(1,1) models for the residuals of the change of the log of per capita real output, the change of the log of per capita real credit, and the change of the log of the loan-todeposit ratio. The residuals are obtained by regressing the change of the log of the variable on an intercept and its lagged value.

Table C1: Estimates of GARCH(1,1) Models for the Residual of the Change of Logs of Per Capita Real Output, Per Capita Real Credit and the Loan-to-Deposit Ratio

\begin{tabular}{lccc}
\hline \hline & $\begin{array}{c}\text { Residual of the Change } \\
\text { of the Log of Per } \\
\text { Capita Real Output }\end{array}$ & $\begin{array}{c}\text { Residual of the Change } \\
\text { of the Log of Per } \\
\text { Capita Real Credit }\end{array}$ & $\begin{array}{c}\text { Residual of the Change } \\
\text { of the Log of Loan- } \\
\text { to-Deposit Ratio }\end{array}$ \\
Constant & $\begin{array}{c}3.11 \mathrm{E}-06^{\dagger} \\
(1.89 \mathrm{E}-06)\end{array}$ & $1.44 \mathrm{E}-05$ & $0.0001^{*}$ \\
& $(8.97 \mathrm{E}-06)$ & $(4.47 \mathrm{E}-05)$ \\
ARCH Effect $(-1)$ & $(0.066)$ & $0.220^{\dagger}$ & 0.024 \\
& $0.737^{*}$ & $(0.121)$ & $(0.051)$ \\
GARCH Effect $(-1)$ & $(0.050)$ & $0.612^{*}$ & -0.699 \\
& $(0.193)$ & $(0.580)$ \\
\hline \hline
\end{tabular}

Note: Sample period: 1973Q1 to 2012Q2. Included observations: 158 after adjustments. Method: ML - ARCH

(Marquardt) - Normal distribution. '*' indicates significance at $5 \%$ level, and ' $\nmid$ ' indicates significance at $10 \%$ level.

The standard errors are given in brackets.

As shown in Table C1, the ARCH and GARCH effects are significant for the residual of the change of the logs of per capita real output and per capita real credit series, providing evidence of time-varying volatility in credit and output. However, there is no evidence of time-varying volatility in the loan-to-deposit ratio. 